\title{
Genome-wide identification, evolutionary and expression analysis of the aspartic protease gene superfamily in grape
}

Rongrong Guo ${ }^{1,2}$, Xiaozhao Xu ${ }^{1,2}$, Bassett Carole ${ }^{3}$, Xiaoqin $\mathrm{Li}^{1,2}$, Min Gao ${ }^{1,2}$, Yi Zheng ${ }^{1}$ and Xiping Wang ${ }^{1,2^{*}}$

\begin{abstract}
Background: Aspartic proteases (APs) are a large family of proteolytic enzymes found in almost all organisms. In plants, they are involved in many biological processes, such as senescence, stress responses, programmed cell death, and reproduction. Prior to the present study, no grape AP gene(s) had been reported, and their research on woody species was very limited.

Results: In this study, a total of 50 AP genes (VVAP) were identified in the grape genome, among which 30 contained the complete ASP domain. Synteny analysis within grape indicated that segmental and tandem duplication events contributed to the expansion of the grape AP family. Additional analysis between grape and Arabidopsis demonstrated that several grape AP genes were found in the corresponding syntenic blocks of Arabidopsis, suggesting that these genes arose before the divergence of grape and Arabidopsis. Phylogenetic relationships of the 30 VVAPs with the complete ASP domain and their Arabidopsis orthologs, as well as their gene and protein features were analyzed and their cellular localization was predicted. Moreover, expression profiles of VVAP genes in six different tissues were determined, and their transcript abundance under various stresses and hormone treatments were measured. Twenty-seven VVAP genes were expressed in at least one of the six tissues examined; nineteen VVAPS responded to at least one abiotic stress, 12 VVAPS responded to powdery mildew infection, and most of the VVAPS responded to SA and ABA treatments. Furthermore, integrated synteny and phylogenetic analysis identified orthologous AP genes between grape and Arabidopsis, providing a unique starting point for investigating the function of grape AP genes.

Conclusions: The genome-wide identification, evolutionary and expression analyses of grape AP genes provide a framework for future analysis of AP genes in defining their roles during stress response. Integrated synteny and phylogenetic analyses provide novel insight into the functions of less well-studied genes using information from their better understood orthologs.
\end{abstract}

Keywords: Synteny analysis, Phylogenetic analysis, Gene expression, Orthologous genes, Grape

\section{Background}

Aspartic proteinases (APs; EC 3.4.23) are widely distributed among living organisms, being found in plants, yeast, nematodes, parasites, fungi and even viruses. These enzymes have been extensively studied and constitute one of the four superfamilies of proteolytic enzymes [1-3]. APs

\footnotetext{
* Correspondence: wangxiping@nwsuaf.edu.cn

${ }^{1}$ State Key Laboratory of Crop Stress Biology in Arid Areas, College of Horticulture, Northwest A\&F University, Yangling, Shaanxi 712100, China ${ }^{2}$ Key Laboratory of Horticultural Plant Biology and Germplasm Innovation in Northwest China, Ministry of Agriculture, Northwest A\&F University, Yangling, Shaanxi 712100, China

Full list of author information is available at the end of the article
}

are usually characterized by the presence of two aspartic acid residues located within the conserved Asp-Thr/SerGly motif responsible for catalytic activity [4]. They are active at acidic $\mathrm{pH}$ and are specifically inhibited by active site blockers such as pepstatin A, diazo-acetyl-norleucine methyl ester (DAN), and 1,2-epoxy-3-(p-nitro-phenoxy) propane (EPNP) [5]. APs are synthesized as single-chain preproenzymes which are subsequently converted to mature enzymes that can function as either monomeric or dimeric proteins during activation. According to the MEROPS database (http://www.merops.ac.uk), APs are now grouped into 14 different families on the basis of

\section{Biomed Central}


their amino acid sequence homology, evolutionary relationships, and tertiary structure; these groups in turn are assembled into six different clans [3]. Plant APs are distributed among several different families (A1, A3, A11 and A12 of clan AA, and family A22 of clan AD), but the majority belong to the A1 family [6].

Plant APs are classified as typical APs, nucellin-like APs and atypical APs [7]. Typical plant AP preproteins contain a C-terminal domain of approximately 50-100 amino acids (called the plant specific insert, PSI) which is removed during protein maturation. Neither their sequences nor structures share significant homology with animal or microbial APs; however, the PSI domain is homologous with the precursor of mammalian saposins [8]. The nucellin-like APs encode proteins similar to nucellin found in barley nucellar cells [9]. Atypical APs display intermediate features between the typical and nucellin-like sequences [7].

Plant APs have been implicated in protein processing and/or degradation in different plant organs. They are believed to play a role in plant senescence, stress responses, programmed cell death, and reproduction [6]. In contrast to APs of animal and microbial origin, plant APs are relatively poorly documented with regard to their biochemistry and physiological functions [10]. Furthermore, most of the analyses on plant APs have been performed in model species such as Arabidopsis [7,11], with little attention paid to woody species like grape.

Grapevine (Vitis vinifera L.) is one of the most important perennial fruit crops worldwide. It has been extensively studied at the physiological and developmental levels and was among the first fruits selected for full genome sequencing [12]. Compared to other perennials, the genome size of $V$. vinifera is relatively small (475 Mb) $[12,13]$, which is similar to rice (Oryza sativa, $430 \mathrm{Mb}$ ) [14] and black cottonwood poplar (Populus trichocarpa, $465 \mathrm{Mb}$ ) [15]. In addition, the grapevine genome has not undergone a recent whole genome duplication (WGD), thus enabling the discovery of ancestral traits and genetic divergence occurring during the course of flowering plant evolution [12]. The release of grape genome data allows us for the first time to carry out the genome-wide identification and analysis of AP gene families in a woody species. Here we systematically identified 50 AP genes including $30 V v A P s$ that contain a complete ASP domain in the grape genome. Phylogenetic and synteny analyses revealed segmental and tandem duplication events that have contributed to the grape AP evolution. We further analyzed protein structures and exon/intron junctions of $V v A P s$. In addition, we determined the expression profiles of grape AP genes in six different tissues, and measured their transcript abundance in response to different phytohormone treatments and under various abiotic and biotic stresses. The results obtained from our study provide a foundation for evolutionary and functional characterization of AP gene families in grape and other plant species.

\section{Methods}

\section{Identification and annotation of grape AP genes}

Grape AP genes were identified by searching grape proteins obtained from the Grape Genome Database $(12 \times$; http://www.genoscope.cns.fr) using the Hidden Markov Model (HMM) profile of ASP domain (PF00026) downloaded from the Pfam database (http://pfam.sanger.ac.uk/). The ASP domain in each identified AP gene was then manually checked for its completeness.

\section{Determination of chromosomal localization and synteny analysis}

The $V v A P$ genes were positioned on grape pseudomolecules available at the Grape Genome Database (12 X). Tandemly duplicated AP genes in the grape genome were defined as adjacent to homologous AP genes on the grape chromosomes or within a sequence distance of $50 \mathrm{~kb}$ [16], with no more than one intervening gene [17]. For synteny analysis, synteny blocks within the grape genome and between grape and Arabidopsis genomes were downloaded from the Plant Genome Duplication Database and those containing grape AP genes were identified.

\section{Sequence alignments and phylogenetic analysis}

A total of 20 APs that lack a complete ASP domain, including $V v A P 1, V v A P 2, V v A P 5, V v A P 7, V v A P 11, V v A P 14$, VvAP15, VvAP19, VvAP20, VvAP22 VvAP23, VvAP26, $V v A P 31, V v A P 37, V v A P 38, V v A P 43, V v A P 47, V v A P 49$ and $V v A P 50$, were excluded from the phylogenetic analysis and further study. The remaining $30 \mathrm{VvAPs}$ and AtAPs were aligned using ClustalX [18]. To compare and define subgroups, we integrated conserved ASP domain sequences of nucellins from barley (GenBank accession no. U87148) [9] into this dataset. The following Arabidopsis genes were selected for predicting the function of their orthologous counterparts in grape: CDR1 (NP_198319, which plays a crucial role in activating resistance of Arabidopsis against microbial pathogens) [11]; PCS1 (NP_195839, the PROMOTION of CELL SURVIVAL 1 gene, which encodes an aspartic protease with an important role in determining the fate of both male and female gametophytes and excessive cell death of developing embryos) [19]; and ASPG1 (NP_188478, the ASPARTIC PROTEASE IN GUARD CELL 1 gene whose over expression conferred drought avoidance via ABA-dependent signalling in Arabidopsis) [20]. Phylogenetic trees were constructed with the MEGA 5.0 software using the neighbor-joining (NJ) method, and the bootstrap test was replicated 1000 times [21]. 


\section{Exon/intron structure analysis of $V v A P$ genes}

The $30 V v A P$ genes with the complete ASP domain were used in this study. The Pfam domain and signal peptide were predicted using SMART (http://smart. embl-heidelberg.de/smart/set_mode.cgi?NORMAL=1) [22]. The diagram of protein structures was constructed with the DOG 1.0 software (http://dog.biocuckoo.org/) [23]. The exon/intron structures of the grape AP genes were determined from alignments of their coding sequences with corresponding genomic sequences using the est2genome program [24]. The diagram of exon/intron structures was obtained using the online Gene Structure Display Server (GSDS: http://gsds.cbi.pku.edu.ch) [25], which exhibited both exon position and gene length.

\section{Plant materials}

Grape tissues, including young roots, stems, leaves, and tendrils, flowers at the fully opening stage, and fruits at 33 days post anthesis were harvested from two year-old 'Kyoho' ( . labrusca $\times V$. vinifera) seedlings grown in the field. 'Kyoho' was also used for high salt, drought stress, and exogenous hormone treatments. Chinese wild Vitis quinquangularis 'Shang-24' was used for powdery mildew inoculation. Both grape species are maintained in the grape germplasm resource orchard of Northwest A\&F University, Yangling, China (3420'N, 108 $\left.24^{\circ} \mathrm{E}\right)$.

\section{Abiotic, hormone and biotic stress treatment}

For abiotic stress, two year-old 'Kyoho' grape seedlings planted in pots were irrigated with $2 \mathrm{dm}^{3} 250 \mathrm{mM} \mathrm{NaCl}$ [26,27]. After treatments for $1 \mathrm{~h}, 3 \mathrm{~h}, 6 \mathrm{~h}, 12 \mathrm{~h}, 24 \mathrm{~h}$ and $48 \mathrm{~h}$, the fully unfolded young leaves were collected. Drought stress was carried out by withholding water from 'Kyoho' seedlings with some modification [28,29]. Briefly, young leaves of the seedlings were harvested at $24 \mathrm{~h}, 48 \mathrm{~h}, 72 \mathrm{~h}, 96 \mathrm{~h}, 120 \mathrm{~h}, 144 \mathrm{~h}$ and $168 \mathrm{~h}$ post treatment. Subsequently, the stressed plants were rewatered to soil saturation and leaves were collected at $48 \mathrm{~h}$ after rewatering. For salt and drought stress, plants watered every three days were used as control.

Hormone treatments were conducted by spraying young leaves with $100 \mu \mathrm{M}$ SA [30,31] or $100 \mu \mathrm{M}$ ABA $[26,32]$ followed by sampling at $0.5 \mathrm{~h}, 1 \mathrm{~h}, 3 \mathrm{~h}, 6 \mathrm{~h}, 12 \mathrm{~h}$, $24 \mathrm{~h}$ and $48 \mathrm{~h}$ post-treatment. Leaves sprayed with sterile distilled water at the same time points were collected as the control.

Pathogen treatment was carried out by inoculating the young leaves of 'Shang-24' with powdery mildew as previously described with minor modifications [33]. Prior to inoculation, leaves were sprayed with sterile water, and leaves were harvested at $6 \mathrm{~h}, 12 \mathrm{~h}, 24 \mathrm{~h}$, $48 \mathrm{~h}, 72 \mathrm{~h}, 96 \mathrm{~h}$ and $120 \mathrm{~h}$ post-inoculation (Hpi). Control plants were simply sprayed with sterile water and not inoculated.
At each time point of each treatment, nine leaves from three separate plants were combined to form one sample. These leaves were immediately frozen in liquid nitrogen and stored at $-80^{\circ} \mathrm{C}$ until use.

Several genes that have been reported to positively respond to abiotic or biotic stress were used to confirm the efficacy of the stress treatments; these included RD22 and CEF4 (induced by drought, salt and/or ABA treatments) [34-36], and PR1 and EDS1 (enhanced by SA treatment and powdery mildew inoculation) [37-40] (Additional file 1).

\section{Semi-quantitative RT-PCR and real-time PCR analysis}

Total RNA was extracted according to Zhang et al. [41], and then treated with 10 units of RNase-free DNase I (TaKaRa Bio Inc., Dalian, China) to remove genomic DNA contamination. For each sample, $1 \mu \mathrm{g}$ of total RNA was used to synthesize first-strand cDNA using SuperScriptII reverse transcriptase (Invitrogen). For the following experiments, the reverse transcription products were diluted to six times. The concentration of the cDNAs was adjusted using the grape Actin1 gene (GeneBank Accession number AY680701) with the primers F (5'-GAT TCT GGT GAT GGT GTG AGT-3') and R (5'-GAC AAT TTC CCG TTC AGC AGT-3') and the grape $E F 1-\alpha$ gene (GeneBank Accession number EC931777) with the primers F (5'-AGG AGG CAG CCA ACT TCA CC-3') and R (5'-CAA ACC CTG CAT CAC CAT TC-3'). Gene-specific primers were designed for the 30 grape AP genes with the complete ASP domain (Additional file 2). For semi-quantitative reverse transcription-PCR (RT-PCR), a $20 \mu$ l reaction volume that included $1 \mu \mathrm{l}$ of cDNA template, $1.6 \mu \mathrm{l}$ of gene-specific primers $(1.0 \mu \mathrm{M}), 9.8 \mu \mathrm{l}$ PCR Master Mix (Tiangen Biotech Co. Ltd., Beijing, China) and $7.6 \mu$ sterile distilled water was used. The PCR parameters were $95^{\circ} \mathrm{C}$ for $3 \mathrm{~min}$; followed by $25-35$ cycles of $95^{\circ} \mathrm{C}$ for $30 \mathrm{~s}, 58^{\circ} \mathrm{C}$ for $30 \mathrm{~s}$, $72^{\circ} \mathrm{C}$ for $25 \mathrm{~s}$, and a final step at $72^{\circ} \mathrm{C}$ for $2 \mathrm{~min}$. Each PCR was replicated three times. The results of semi-quantitative RT-PCR were quantified using the Gene Tools software, and the log-transformed values of the relative transcript abundance of $V v A P$ genes under abiotic, hormone and biotic stress treatment compared to the control were used for hierarchical cluster analysis with Genesis software.

Quantitative real-time PCR analysis was conducted with an IQ5 real-time PCR instrument (Bio-Rad, Hercules, CA, USA). Each reaction was carried out in triplicate with a reaction volume of $20 \mu \mathrm{l}$ containing $1.6 \mu \mathrm{l}$ of gene-specific primers $(1.0 \mu \mathrm{M}), 1.0 \mu \mathrm{l}$ of cDNA, $10 \mu \mathrm{l}$ of SYBR green (TaKaRa Bio Inc.), and 7.4 $\mu \mathrm{l}$ sterile distilled water. The PCR parameters were $95^{\circ} \mathrm{C}$ for 30s, followed by 40 cycles of $95^{\circ} \mathrm{C}$ for $5 \mathrm{~s}$ and $60^{\circ} \mathrm{C}$ for 30s. Relative expression levels were analyzed using the IQ5 software and the normalizedexpression method. 
Database searches of the expression patterns of AtAP genes The expression patterns of AtAP genes under powdery mildew infection and SA treatment were obtained from The Gene Expression Atlas of EMBL-EBI (http://www. ebi.ac.uk/gxa/) [42]. The expression patterns of these genes under salt and drought stresses and ABA treatment were obtained from Weigel World database (http://jsp. weigelworld.org/expviz/expviz.jsp) [43].

\section{Targeting signals prediction of the grape AP genes}

The targeting signals of grape AP genes were predicted with PSORT (http://psort.hgc.jp/form.html) [44].

\section{Results}

Genome-wide identification of AP genes in the $V$. vinifera genome

A total of 50 genes in the grape genome were identified as possibly AP genes (Table 1). Among them, 30 have the two complete Asp-Thr/ Ser-Gly motifs, while the others have either a single motif or an incomplete ASP domain. A total of 46 AP genes could be mapped to specific chromosomes and were named from $V v A P 1$ to $V v A P 46$ based on their order on the chromosomes (Figure 1, chromosomes 1-19). Four AP genes (GSVIVT01006876001, GSVIVT01006894001, GSVIVT01006895001 and GSVIV T01007227001) that could not be conclusively mapped to any chromosomes were named $V v A P 47-V v A P 50$, respectively. Furthermore, additional AP genes could also exist in the grape genome, awaiting identification by improved annotation methodology.

\section{Expansion patterns of AP genes in grape}

Segmental and tandem duplications are the main mechanisms leading to gene family expansions [45]. Thirty six AP genes involved in tandem duplications had been reported in rice [46]. In the present study, we also identified 11 tandemly duplicated AP genes $(V v A P 3 / V v A P 4$, $V v A P 5-V v A P 8, \quad V v A P 22-V v A P 24$, and $V v A P 34 / V v A P 35$ located on grape chromosomes 2, 4, 8 and 14, respectively) (Figure 1). Furthermore, we examined the segmentally duplicated blocks within the grape genome and found that there were 9 pairs of grape AP genes associated with segmental duplications (Figure 1), $V v A P 10 / V v A P 34$, VvAP16/VvAP44, VvAP40/VvAP18, VvAP42/VvAP17, VvAP27/VvAP45, VvAP32/VvAP21, VvAP13/VvAP25, $V v A P 22 / V v A P 14$, including two tandemly duplicated genes ( $V v A P 22$ and $V v A P 34)$ (Additional file 3). In summary, half of the $V v A P$ gene family members were associated with either segmental or tandem duplication events.

\section{Evolutionary relationships of AP genes between grape and Arabidopsis}

To further explore the origin and evolutionary process of grape AP genes, we analyzed the comparative synteny map between grape and Arabidopsis genomes. Arabidopsis is among the most important model plant species, particularly with regard to AP genes since the functions of some of them have been well characterized. Thus through comparative genomics we can determine the origin and diversification of grape APs based on their Arabidopsis homologs.

Large-scale syntenies containing 23 AP genes in grape and 25 in Arabidopsis were identified (Figure 2). In addition, four genes in the Arabidopsis genome that were not annotated as AP genes were found to share synteny with grape AP genes (Additional file 4). Regarding the single grape-to-Arabidopsis AP gene correspondences, the syntenies were unambiguous and included the following orthologous pairs: VvAP1-At1g25510, VvAP2At5g47510, VvAP11-At5g19100, VvAP22-At3g52500, VvAP26-At1g79720, VvAP30-At4g30030, VvAP33-At3g54400, VvAP39-At1g49050, VvAP46-At3g12700, indicating these genes should have been in the genome of the last common ancestor of grape and Arabidopsis. Among these, neither At5g47510 nor At5g19100 belonged to the Arabidopsis AP gene family; instead At5g47510 has a SEC14 (domain in homologues of a S. cerevisiae phosphatidylinositol transfer protein) and a CRAL-TRIO-N (a protein structural domain that binds small lipophilic molecules) domain and At5g19100 has a PDB domain 1T6G|B, both of which were also included in $V v A P 2$ and $V v A P 11$, respectively. More challenging for syntenic interpretation were cases where grape segmental duplications corresponded to a single Arabidopsis gene or where a single grape gene corresponded to multiple Arabidopsis genes. The first situation included VvAP13/VvAP25-At5g22850, VvAP13/ VvAP25-At2g36670, VvAP16/VvAP44-At3g50050, VvAP17/ VvAP42-At5g10080, VvAP18/VvAP40-At1g77480, VvAP21/ VvAP32-At2g39710, VvAP21/VvAP32-At5g02190, VvAP27/ VvAP45-At1g11910, VvAP27/VvAP45-At1g62290, VvAP27/ VvAP45-At4g22050; whereas the second included VvAP13At1g08210/At2g36670/At5g22850, VvAP21-At2g39710/ At5g02190, VvAP25-At2g36670/At5g22850, VvAP27-At1g1 1910/At1g62290/At4g04460/At4g22050, VvAP31-At2g42 980/At3g59080, VvAP32-At2g39710/At3g46620/At5g59550/ At5g02190, VvAP37-At1g01300/At3g61820, VvAP40-At1g7 7480/At1g44130, VvAP44-At3g50050/At5g43100, VvAP45At1g11910/At1g62290/At4g22050. Among these, two of the four orthologs of VvAP32 in Arabidopsis (At3g46620 and At5g59550) were not AP genes; however, both of them had a RING and DUF1117 domain (data not shown), which could also be detected in $V v A P 32$, implying that $V v A P 32$ may have undergone multiple significant chromosomal rearrangement and fusions. Finally, a third case was identified where two duplicated grape genes corresponded to multiple Arabidopsis genes. These were VvAP13/VvAP25-At2g366 70/At5g22850, VvAP21/VvAP32-At2g39710/At5g02190, and VvAP27/VvAP45-At1g11910/At1g62290/At4g22050. 
Table 1 AP genes in grape

\begin{tabular}{|c|c|c|c|c|c|c|c|c|}
\hline Group & Gene & Gene locus ID & Accession no. & Chromosome & Start & End & $\begin{array}{l}\text { Predicted gene } \\
\text { length(bp) }\end{array}$ & $\begin{array}{l}\text { Predicted ORF } \\
\text { length(bp) }\end{array}$ \\
\hline & VVAP1 & GSVIVT01011932001 & CBI27051.3 & chr1 & 2921237 & 2927383 & 6147 & 771 \\
\hline & VVAP2 & GSVIVT01001318001 & CBI31923.3 & chr2 & 5263175 & 5284039 & 20865 & 2346 \\
\hline$C$ & VVAP3 & GSVIVT01036932001 & CBI29231.3 & chr2 & 17430558 & 17432766 & 2209 & 927 \\
\hline \multirow[t]{4}{*}{ C } & VVAP4 & GSVIVT01036930001 & CBI29230.3 & chr2 & 17439361 & 17448268 & 8908 & 1629 \\
\hline & VVAP5 & GSVIVT01036013001 & CBI21175.3 & chr4 & 7189959 & 7192597 & 2639 & 1161 \\
\hline & VVAP6 & GSVIVT01036015001 & CBI21177.3 & chr4 & 7244098 & 7247313 & 3216 & 1131 \\
\hline & VvAP7 & GSVIVT01036017001 & CBI21178.3 & chr4 & 7263244 & 7279815 & 16572 & 1119 \\
\hline C & VVAP8 & GSVIVT01036018001 & XM_002268722 & chr4 & 7315581 & 7317297 & 1717 & 1383 \\
\hline C & VVAP9 & GSVIVT01019071001 & XM_002277022 & chr4 & 17094880 & 17107573 & 12694 & 1443 \\
\hline \multirow[t]{2}{*}{ A1 } & VVAP10 & GSVIVT01017701001 & CBI26025.3 & chr5 & 2775453 & 2778471 & 3019 & 1503 \\
\hline & VVAP11 & GSVIVT01017894001 & CBI26188.3 & chr5 & 4453167 & 4455917 & 2751 & 1203 \\
\hline C & VvAP12 & GSVIVT01031690001 & CBI39464.3 & chr5 & 20228612 & 20244419 & 15808 & 1434 \\
\hline \multirow[t]{3}{*}{ C } & VvAP13 & GSVIVT01031432001 & XM_002272085 & chr6 & 18652672 & 18658561 & 5890 & 1455 \\
\hline & VvAP14 & GSVIVT01036053001 & CBI28265.3 & chr6 & 21340808 & 21342747 & 1939 & 1341 \\
\hline & VvAP15 & GSVIVT01028308001 & CBI37099.3 & chr7 & 5960288 & 5965597 & 5309 & 900 \\
\hline C & VvAP16 & GSVIVT01000170001 & CBI33735.3 & chr7 & 15840160 & 15846953 & 6793 & 1902 \\
\hline$C$ & VVAP17 & GSVIVT01022186001 & CBI21469.3 & chr7 & 17268969 & 17274776 & 5807 & 1593 \\
\hline \multirow[t]{3}{*}{ B } & VVAP18 & GSVIVT01022355001 & XM_002273952 & chr7 & 18933005 & 18936614 & 3610 & 1281 \\
\hline & VvAP19 & GSVIVT01022392001 & CBI21639.3 & chr7 & 19580451 & 19581940 & 1490 & 837 \\
\hline & VVAP20 & GSVIVT01025811001 & CBI32837.3 & chr8 & 11598470 & 11608650 & 10181 & 1368 \\
\hline \multirow[t]{3}{*}{ C } & VVAP21 & GSVIVT01034136001 & CBI30526.3 & chr8 & 14910379 & 14911704 & 1326 & 1140 \\
\hline & VvAP22 & GSVIVT01033940001 & CBI30375.3 & chr8 & 16541310 & 16569287 & 27978 & 771 \\
\hline & VVAP23 & GSVIVT01033937001 & CBI30373.3 & chr8 & 16581910 & 16588393 & 6484 & 657 \\
\hline$C$ & VvAP24 & GSVIVT01033935001 & CBI30372.3 & chr8 & 16595281 & 16597123 & 1843 & 1338 \\
\hline \multirow[t]{2}{*}{ C } & VVAP25 & GSVIVT01033723001 & XM_002263093 & chr8 & 18335899 & 18342508 & 6610 & 1509 \\
\hline & VvAP26 & GSVIVT01016100001 & CBI25263.3 & chr9 & 18973023 & 18975323 & 2301 & 1080 \\
\hline A1 & VvAP27 & GSVIVT01012684001 & XM_003632893 & chr10 & 634034 & 638859 & 4826 & 1290 \\
\hline $\mathrm{C}$ & VVAP28 & GSVIVT01026281001 & CBI29076.3 & chr10 & 15521671 & 15522975 & 1305 & 1305 \\
\hline C & VvAP29 & GSVIVT01034372001 & CBI35367.3 & chr10 & 17284723 & 17286494 & 1772 & 1566 \\
\hline \multirow[t]{2}{*}{$C$} & VVAP30 & GSVIVT01010876001 & XM_002265511 & chr11 & 16540456 & 16541682 & 1226 & 1227 \\
\hline & VvAP31 & GSVIVT01020842001 & CBI22091.3 & chr12 & 1179799 & 1181100 & 1301 & 1083 \\
\hline$C$ & VVAP32 & GSVIVT01016510001 & CBI31649.3 & chr13 & 3269121 & 3294047 & 24927 & 2286 \\
\hline $\mathrm{C}$ & VVAP33 & GSVIVT01036671001 & CBI35120.3 & chr13 & 20059866 & 20062297 & 2431 & 963 \\
\hline A1 & VvAP34 & GSVIVT01031329001 & XM_002276327 & chr14 & 327811 & 331186 & 3376 & 1509 \\
\hline $\mathrm{A} 1$ & VvAP35 & GSVIVT01031327001 & CBI39668.3 & chr14 & 337889 & 340868 & 2980 & 1293 \\
\hline \multirow[t]{3}{*}{ C } & VvAP36 & GSVIVT01019297001 & CBI39998.3 & chr15 & 1765842 & 1766963 & 1122 & 1005 \\
\hline & VVAP37 & GSVIVT01027158001 & CBI40559.3 & chr15 & 17367842 & 17369993 & 2152 & 1311 \\
\hline & VvAP38 & GSVIVT01024459001 & CBI26572.3 & chr16 & 2849198 & 2849563 & 366 & 366 \\
\hline B & VvAP39 & GSVIVT01008267001 & CBI15437.3 & chr17 & 3799065 & 3805978 & 6913 & 1422 \\
\hline$B$ & VVAP40 & GSVIVT01008844001 & CBI18999.3 & chr18 & 2734587 & 2737586 & 3000 & 1173 \\
\hline C & VvAP41 & GSVIVT01008883001 & CBI19032.3 & chr18 & 3102029 & 3103369 & 1341 & 1149 \\
\hline \multirow[t]{2}{*}{$C$} & VVAP42 & GSVIVT01008978001 & CBI19115.3 & chr18 & 3994150 & 4000643 & 6494 & 1566 \\
\hline & VvAP43 & GSVIVT01009155001 & CBI19249.3 & chr18 & 5617213 & 5618770 & 1558 & 576 \\
\hline C & VvAP44 & GSVIVT01009385001 & XM_002283222 & chr18 & 7918070 & 7925298 & 7229 & 1980 \\
\hline $\mathrm{A} 1$ & VVAP45 & GSVIVT01037685001 & XM_002279013 & chr19 & 6870994 & 6878047 & 7054 & 1545 \\
\hline C & VvAP46 & GSVIVT01036694001 & CBI24128.3 & chr19 & 23803974 & 23806961 & 2988 & 1137 \\
\hline
\end{tabular}


Table 1 AP genes in grape (Continued)

\begin{tabular}{ccccccccc}
\hline & VVAP47 & GSVIVT01006876001 & CBI29432.3 & chrUn & 28781234 & 28782604 & 1371 & 1011 \\
\hline C & VVAP48 & GSVIVT01006894001 & XM_002269844 & chrUn & 28931224 & 28934832 & 3609 & 1557 \\
\hline & VVAP49 & GSVIVT01006895001 & XM_003635291 & chrUn & 28936408 & 28937470 & 1063 & 450 \\
\hline & VVAP50 & GSVIVT01007227001 & CBI25840.3 & chrUn & 30964385 & 30966631 & 2247 & 906 \\
\hline
\end{tabular}

\section{Phylogenetic analysis of AP genes from grape and Arabidopsis}

Among the 50 grape AP genes, 20 have an incomplete conservative ASP domain, and some of them can be mapped to synteny blocks between grape and Arabidopsis AP genes (VvAP1, VvAP22, VvAP26, VvAP31 and $V v A P 37)$. As a result, we consider them to be members of the grape AP gene family. But since the main focus of this study was to investigate AP members bearing complete ASP domain, these 20 AP genes were therefore not used to construct the phylogenetic tree. The phylogenetic tree was constructed using the conserved ASP domain sequences of the remaining 30 grape AP genes and the AtAPs, as well as one family of reference genes (nucellins) (Figure 3). Three categories (A, B and C) were resolved, similar to those described in Arabidopsis and rice $[7,46]$. Category $\mathrm{A}$, which has been divided into A1 and A2 subgroups, containing five $V v A P S$ and three AtAPs in A1, represented typical aspartic proteases. Two additional AtAPs (At4g22050 and At1g69100) were included in subgroup A2; these genes do not have the PSI, but do possess other sequence elements that indicate they are more closely related to typical aspartic proteases than to any other sequences found in the Arabidopsis genome. Category $\mathrm{B}$ with three $V v A P s$ and four AtAPs consisted of nucellin-like APs. Category C, composed of atypical aspartic proteases, was the largest group with $22 V v A P$ members and 43 AtAP members. Some researchers have divided category $\mathrm{C}$ further into five subgroups $[7,46]$, but the criterion for classification was non-uniform, so in this study, the genes in category $\mathrm{C}$ were not classified further into subgroups. The rooted

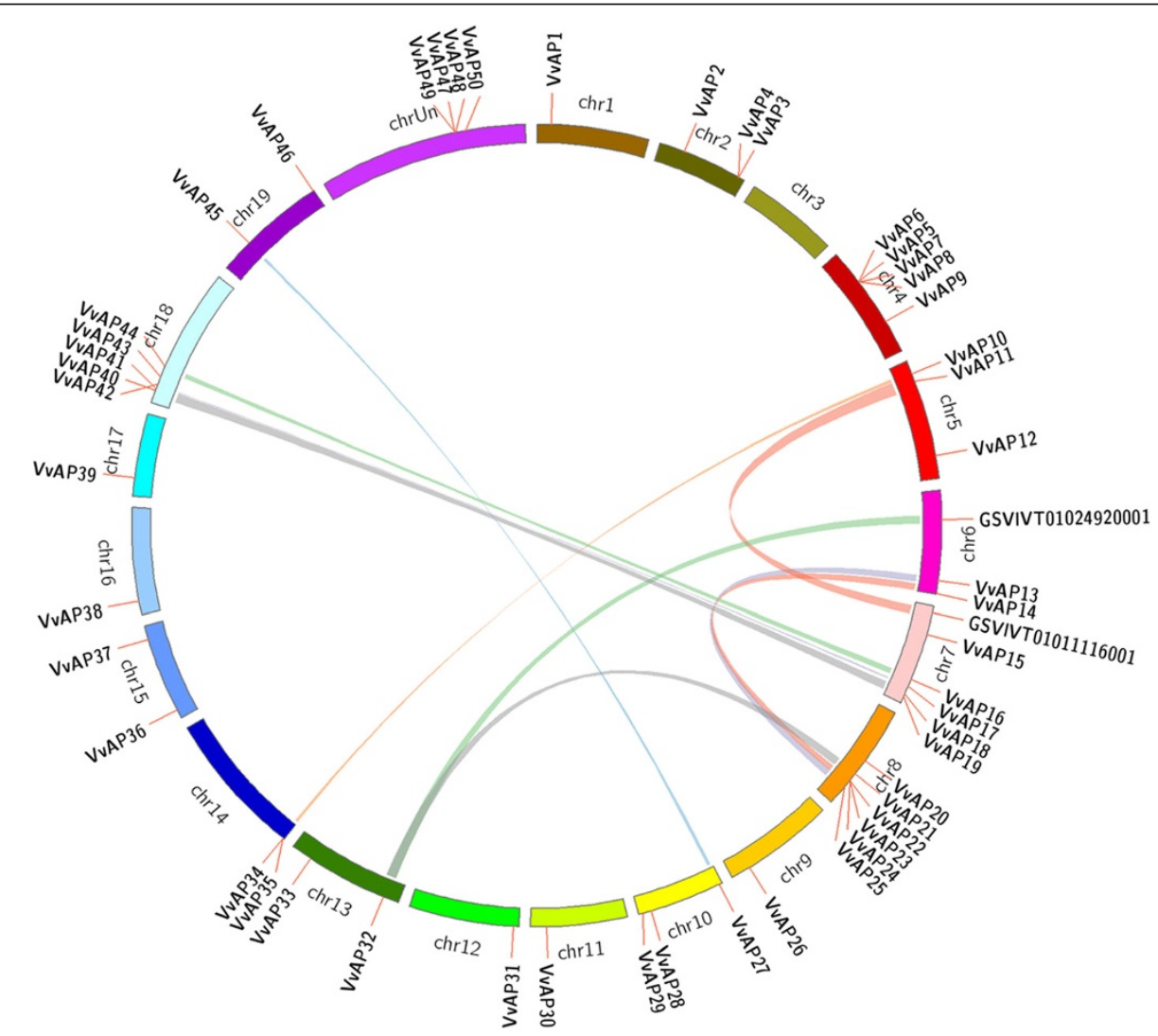

Figure 1 Distribution and synteny analysis of AP genes on grape chromosomes. AP genes are indicated by vertical orange lines. Colored bars denote syntenic regions of the grape AP genome. 


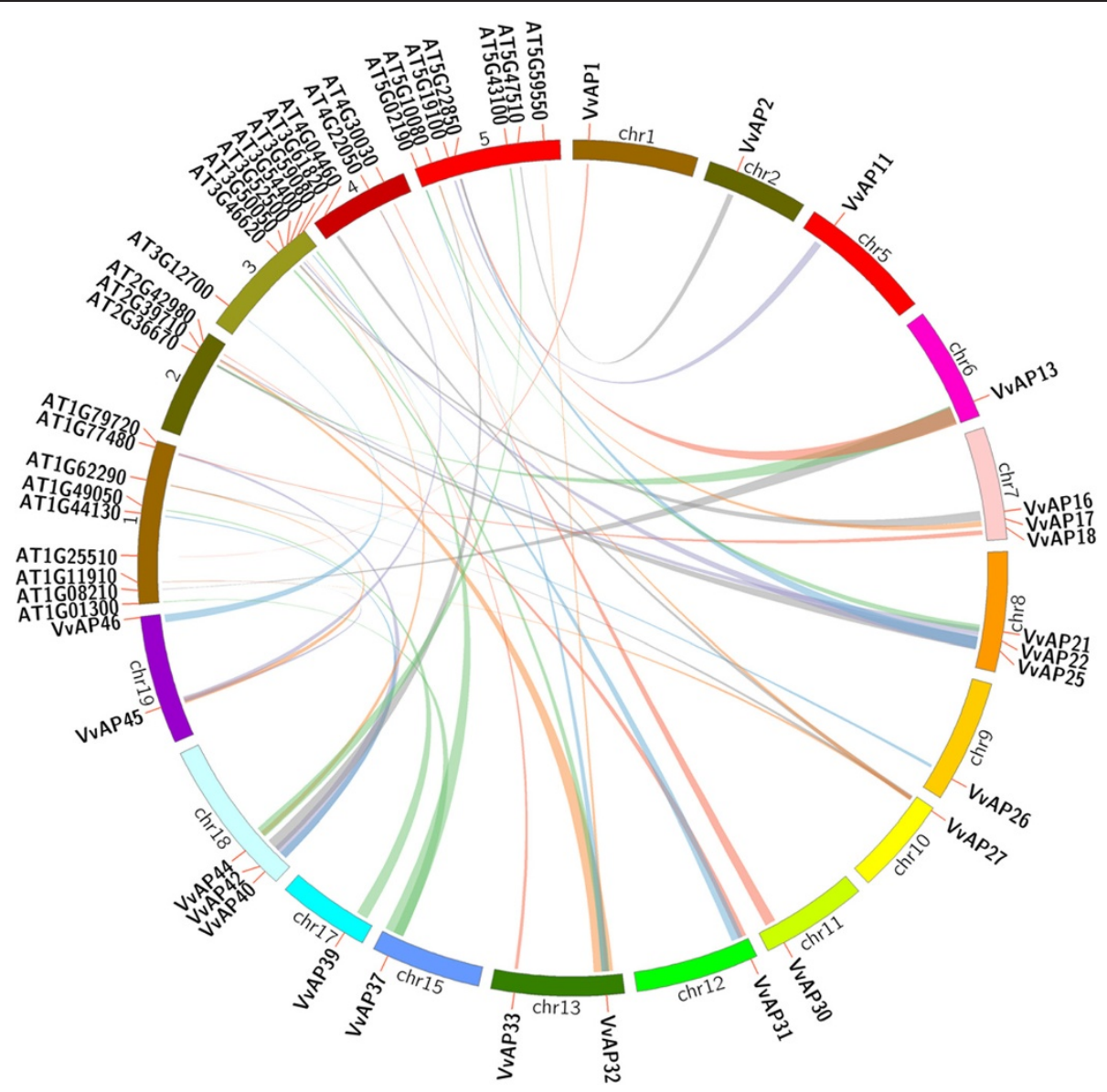

Figure 2 Synteny analysis of AP genes between grape and Arabidopsis. Grape and Arabidopsis AP genes are indicated by vertical orange lines. Colored bars denote syntenic regions between grape and Arabidopsis AP chromosomes.

phylogenetic tree of ASP domains was also used to identify putative orthologs in Arabidopsis and grape (Additional file 5).

\section{Sequence and structure analysis of grape AP genes}

Phylogenetic analysis was also carried out using the conserved amino acid sequences of the 30 grape AP gene family members identified here (Figure 4A). The topology was similar to that constructed with AP sequences from grape and Arabidopsis (Figure 3) and, likewise, AP proteins from the same families within grape clustered together. One exception was the protein $V v A P 24$, which had fallen into group $\mathrm{C}$ in the twospecies analysis, while in the grape analysis it clustered together with the members of group A, being the most divergent member of the AP family.

To provide further confirmation of the evolutionary relationships among the grape AP genes, we determined the distribution of their conserved domains (Figure $4 \mathrm{~B}$ ). By consensus, a $V v A P$ protein has the following basic structure: a signal peptide, a propeptide, and an ASP domain with two active sites [47]. All of the $50 \mathrm{VvAP}$ proteins identified were predicted to contain at least one ASP domain, but 20 of them had just one active site. These we excluded from the phylogenetic analyses between and within species. Sixty percent of the remaining $V v A P$ proteins (18 sequences) had the basic structure of a signal peptide and two active sites. In addition 13 $V v A P$ proteins had at least one transmembrane domain or one low complexity domain. Five $V v A P s$ were identified as typical $V v A P$ proteins, and all of them had a SapB domain and a SapB_1 domain located in the PSI sequence. One atypical protein, VvAP32, had a RING domain and a DUF1117 domain.

The divergence of exon/intron structure often plays a key role in the evolution of gene families. Therefore, the exon/intron structures of the grape APs were examined (Figure 4C) to gain further insight into their possible structural evolution. Our results indicated that there was a strong correlation between the phylogeny and exon/ intron structure, meaning that genes clustering together generally possessed similar structures. In summary, $V v A P$ genes in category $\mathrm{A}$ had 13 exons, those in category $\mathrm{B}$ ranged from eight to nine. On the other hand, the number 


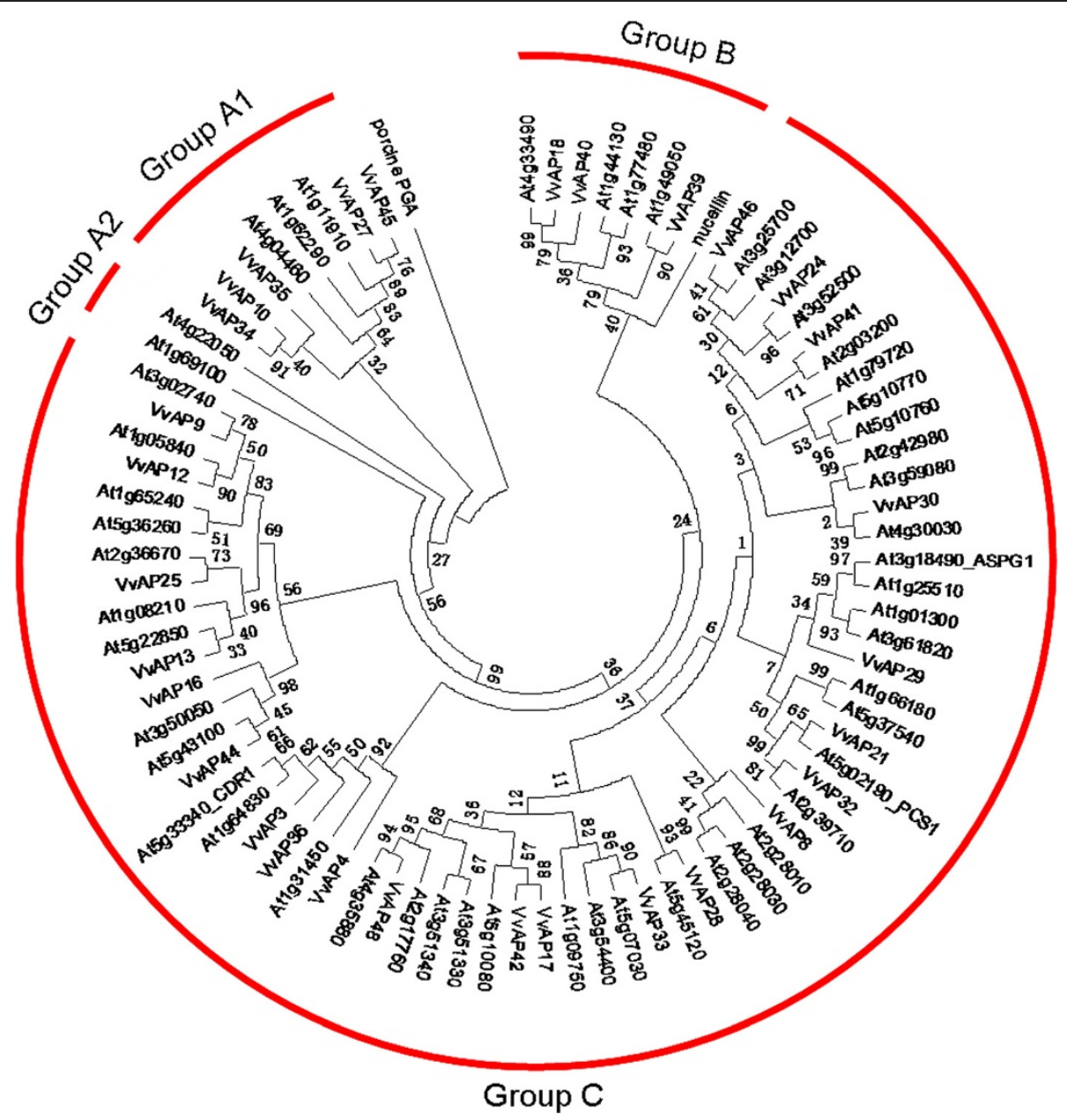

Figure 3 Phylogenetic analysis of grape and Arabidopsis APs. The conserved ASP domains of all VVAP and AtAP proteins were aligned with Clustal X 2.0.12, and the phylogenetic tree was constructed using the neighbor-joining method in MEGA 5.0. Porcine pepsin A was used as the outgroup. VVAPS that had incomplete conserved ASP domains were not included in the phylogenetic tree analysis.

of exons in the $V v A P$ category $\mathrm{C}$ genes varied considerably, with nine of the 22 category $C$ genes ranging from nine to 12 exons, while the others had only one to four exons. VvAP32 was an exception, having two additional domains and seven exons, suggesting that it may have acquired the two additional domains during evolution.

\section{Expression profiles of grape AP genes in different tissues}

Semi-quantitative RT-PCR was used to detect the expression patterns of the 30 grape AP genes under normal growth conditions in six different tissues: roots, stems, leaves, flowers, fruits and tendrils. Of these, 27 genes (90\%) were expressed in at least one of the six tissues (Figure 5). Expression of the other three genes ( $V v A P 4$, VvAP30, VvAP41) was not detected by RT-PCR in any of the tissues tested (data not shown). Twenty-one $V v A P$ genes were expressed in all tested tissues but varied in expression levels. For example, VvAP10 showed high levels of expression in roots, leaves and flowers, but much lower expression in the stems, fruits and tendrils. The other six genes, VvAP3, VvAP8, VvAP33, VvAP35, VvAP36 and $V v A P 39$, showed tissue-specific expression patterns. It is worth noting that the transcripts of $V v A P 3$ and $V v A P 36$ were neither detected in leaves under normal growth conditions, nor in leaves under stress and hormone treatments (data not shown). Therefore, in addition to $V v A P 4, V v A P 30$ and $V v A P 41$, these genes were not studied further.

Expression patterns of grape AP genes under different stress and exogenous hormone treatment conditions

Different approaches have been taken to improve plant stress tolerance, including manipulating and reprogramming the expression of endogenous stress-related genes. Therefore, identification and functional characterization of potential stress-related genes provides fundamental information for future improvement of plant stress tolerance. In the present study, we investigated the response 


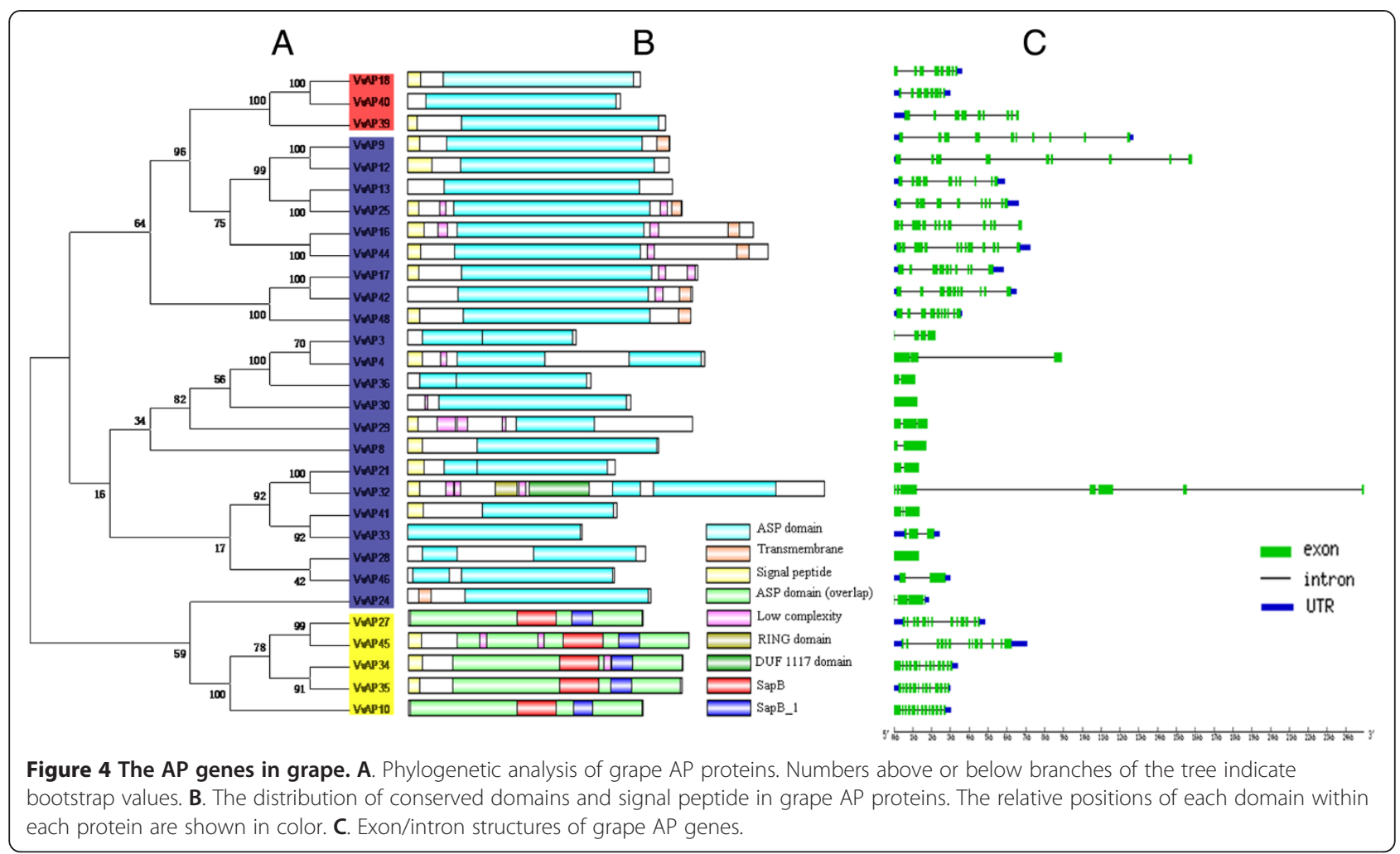

of grape AP genes to various abiotic and biotic stress conditions, as well as hormone treatments.

\section{Abiotic stress}

To determine whether $V \nu A P$ genes are responsive to osmotic stresses in grape leaves, semi-quantitative RT-PCR was used to test their transcript abundance under salt and drought stress treatments. As shown in Figure 6 (see also Additional file 6, Additional file 7), 19 genes responded to at least one stress treatment. Three grape AP genes ( $V v A P 17, V v A P 27$ and $V v A P 44)$ exhibited enhanced transcript abundance by both treatments, whereas eight (VvAP8, VvAP12, VvAP16, VvAP32,
VvAP33, VvAP34, VvAP35 and VvAP46) were downregulated. In particular, the transcript abundance of VvAP8, VvAP16, VvAP24, VvAP33, VvAP34 and VvAP35 decreased gradually with the time under drought stress, but their transcript abundance increased after rewatering, while the other genes exhibited constitutive transcript abundance, or were up- or down-regulated. Interestingly, $V v A P 25$ was up-regulated in response to salt stress, but down-regulated in response to drought stress. In contrast, $V v A P 28$ and VvAP39 transcript abundance decreased when treated with salt, but increased in response to drought. $V v A P 13$ was up-regulated when exposed to salt stress, while $V v A P 10$ exhibited decreased transcript

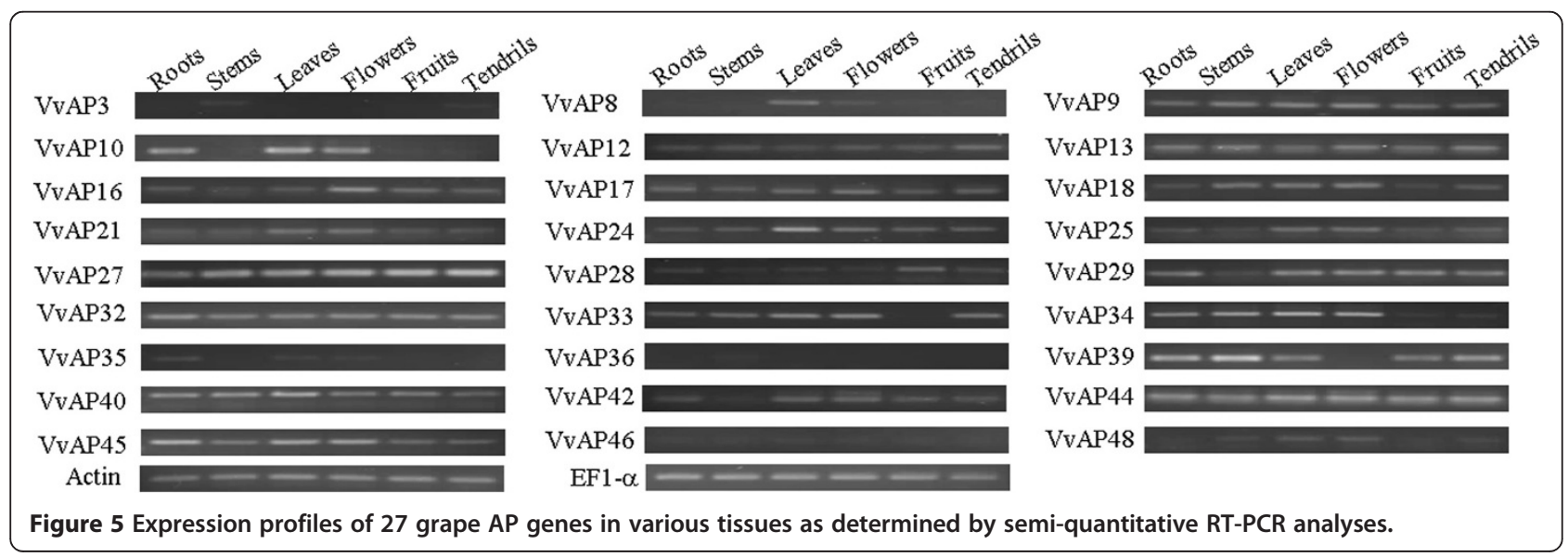




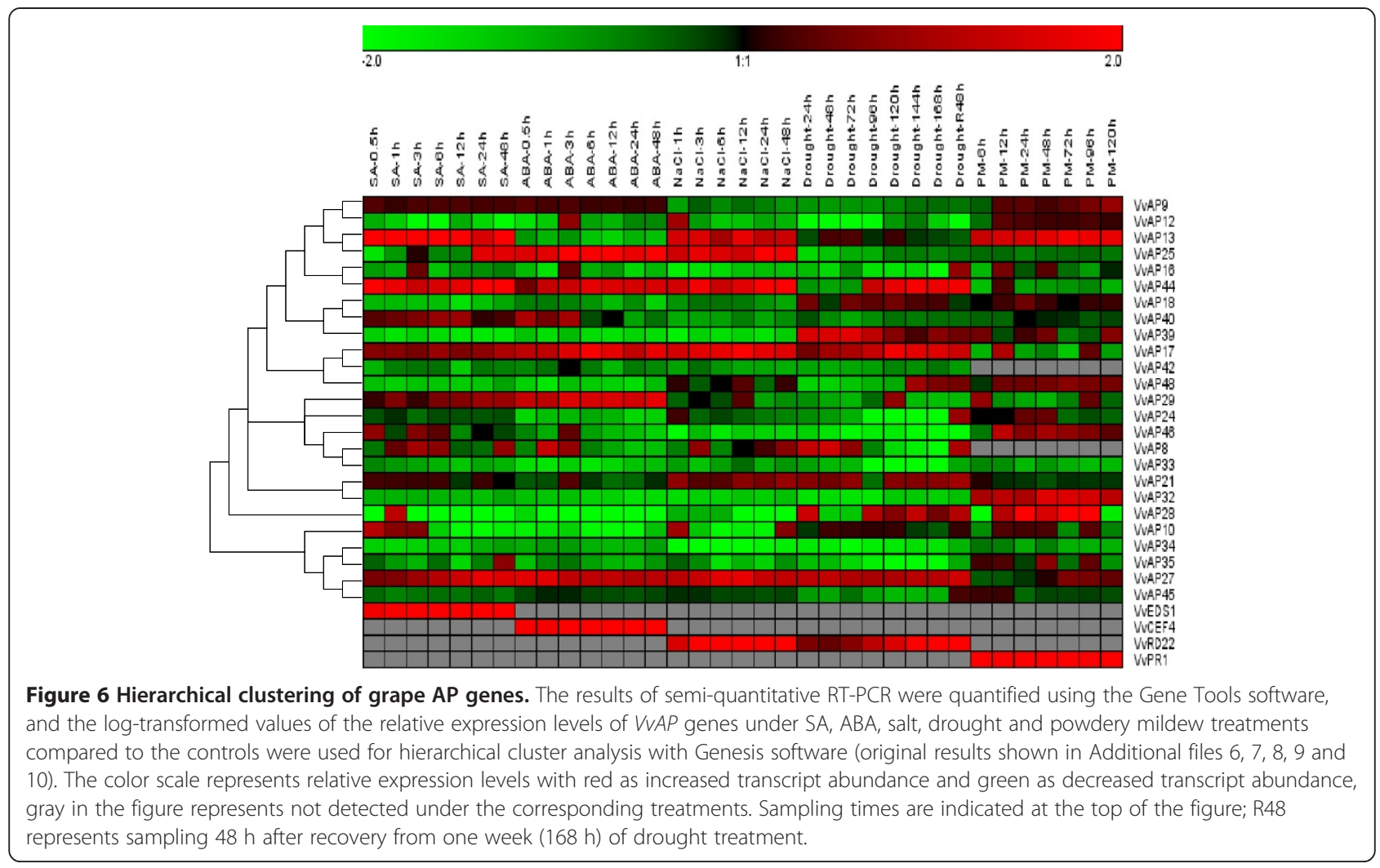

abundance; these two genes were not affected by drought treatment. The transcript abundance of $V v A P 8, V v A P 24$ and $V v A P 45$ were decreased by drought stress, but not affected by salt stress. The transcript abundance of the other six genes (VvAp9, VvAP18, VvAP21, VvAP29, $V v A P 40, V v A P 42)$ was not regulated by either osmotic stress treatment. Transcript abundance of three randomly selected AP genes under either treatment were verified by real-time RT-PCR (Additional file $6 \mathrm{~B}$ and Additional file $7 \mathrm{~B})$, indicating that the results of the real-time and semiquantitative RT-PCR were consistent.

\section{Biotic stress}

Increasing evidence suggests that AP genes play important roles in response to pathogen infection $[11,48]$. The stress responses of the 30 grape AP genes were therefore investigated by semi-quantitative RT-PCR to obtain their transcript abundance under powdery mildew infection. VvAP3, VvAP4, VvAP30, VvAP36 and VvAP41 whose transcript abundance could not be detected in the leaves of 'Kyoho', were also not expressed in the leaves of 'Shang-24'. Neither VvAP8 nor VvAP42 were expressed in the mock leaves or in the inoculated leaves of 'Shang-24' (data not shown). Of the remaining 23 genes, half responded to powdery mildew infection, including $V v A P 13$, $V v A P 28, V v A P 32$ and $V v A P 46$ which were up-regulated and VvAP16, VvAP17, VvAP25, VvAP29, VvAP33, VvAP34,
VvAP35 and VvAP44 which were down-regulated (Figure 6 and Additional file 8). The transcript abundance of $V v A P 13$ in infected leaves peaked at $72 \mathrm{~h}$, whereas $V v A P 32$ increased slightly at $6 \mathrm{~h}$ and remained constant for the duration of the measurement period. $V v A P 46$ peaked at $12 \mathrm{~h}$ post-inoculation. Although the transcript abundance of $V v A P 28$ in infected leaves was weaker than in mock-inoculated leaves at 6 and $120 \mathrm{~h}$ post-infection, its transcript abundance was elevated from 12-96 $\mathrm{h}$ post-infection. The efficacy of semi-quantitative RT-PCR was also verified by determining the transcript abundance of three randomly selected AP genes under powdery mildew infection using real-time quantitative RT-PCR (Additional file 8B); both were in agreement.

\section{Hormone treatment}

The plant hormone, salicylic acid (SA), is a critical factor in plant responses to pathogen infection [49]. Analysis of transcript abundance from 'Kyoho' grape leaves sprayed with SA showed that seven of the 25 VvAPs (VvAP13, VvAP17, $V v A P 25, V v A P 27, V v A P 29, V v A P 40$ and $V v A P 44)$ were upregulated by different degrees upon treatment, whereas 11 VvAP genes (VvAP12, VvAP16, VvAP18, VvAP28, VvAP32, VvAP33, VvAP34, VvAP35, VvAP39, VvAP42 and VvAP48) were down-regulated. $V v A P 10$ transcript levels were high at the first three sampling times after SA treatment, but declined thereafter (Figure 6 and Additional file 9). 
ABA is known to play a central role in the response of plants to various types of abiotic stress [50]. Analysis of transcript abundance from 'Kyoho' leaves treated with exogenous ABA indicated that seven of the $25 V v A P$ genes analyzed exhibited increased expression at different times after treatment (Figure 6 and Additional file 10). For example, the transcript abundance of $V v A P 17, V v A P 25$ and $V v A P 44$ was induced at $3 \mathrm{~h}$ after treatment, while that of $V v A P 29$ was essentially constitutive throughout the experiment. The transcript abundance of $V v A P 8$ peaked at $1 \mathrm{~h}$ after treatment, where as both $V v A P 27$ and $V v A P 40$ peaked at $0.5 \mathrm{~h}$ post-treatment. Approximately half of the analyzed genes exhibited decreased transcript abundance, whereas the levels of $V v A P 9, V v A P 21, V v A P 42$ and $V \nu A P 45$ remained unchanged after treatment.

\section{Discussion}

Members of the plant AP family have been implicated in various physiological and developmental processes, including protein processing and degradation, senescence, stress response, programmed cell death and reproduction. However, virtually nothing is known about this family in woody species. Since grapevine is one of the most important fruit trees worldwide, and various forms of both biotic and abiotic stresses have a serious impact on its production and quality. Further study on stress-related responses in this genus could prove to be a significant asset. Therefore, we have sought to undertake the genome-wide identification of AP genes in grape, and provide clues regarding both their evolutionary histories and expression diversity with respect to stress-related conditions.

\section{Tandem and segmental duplications contributed to the expansion of the grape AP gene family}

Gene duplication, including tandem, segmental and whole genome duplications, has played an important role in the evolution of various organisms [51], and land plants have undergone abundant gene duplication throughout their evolutionary history [52]. Since the grapevine genome has not undergone any recent whole genome duplication events [12], segmental and tandem duplications would be the two main causes of gene family expansions in grape, although there is debate on the exact nature and timing of these events in grape $[12,13]$. In this study, 26 of 46 grape AP genes which could be precisely located on chromosomes were associated with either tandem or segmental duplication events (Figure 1 and Additional file 3), consistent with findings in rice whereby 51 of $93 \mathrm{AP}$ genes were located in either tandemly or segmentally duplicated regions [46]. Taken together, this suggests that tandem and segmental duplications likely played an important role in the expansion of the AP family in plants. Although the duplicated grape AP genes identified here have a common ancestor, we could not conclude from the work conducted here what the ancestral functions and expression patterns may have been, since gene duplication is considered to provide the raw material for evolution and duplicated genes which, if survive, could undergo substantial changes in their structures and/or regulatory mechanisms allowing them to assume novel roles [53].

\section{The structural conservative and divergence of grape AP genes}

Although several models of the genome evolution have been proposed from comparative genomic analyses of model organisms [54-56], little attention has been paid to the structural evolution of duplicated gene families [57]. In fact, exon/intron diversification of gene family members has played an important role in the evolution of multiple gene families through three main types of mechanism: exon/intron gain/loss, exonization/pseudoexonization, and insertion/deletion [51]. It was obvious that grape AP genes within the same phylogenetic clade (Figure 4A) possessed highly similar exon/intron structures (Figure $4 \mathrm{C}$ ) and most of the grape AP genes that clustered in the same phylogenetic clade were segmental or tandem duplications (Figure 1 and Figure 4A). Based on the results presented here, it is clear that the expansion of the grape AP family was the result of either segmental or tandem duplication. This is consistent with findings in rice [46], despite the fact that the numbers of exons of the $V v A P$ genes in category $C$ (1-4 or 9-12) were different from those of the OsAP genes in the same category (less than four).

Exon/intron gain/loss and divergence in exon/intron length which were observed within the coding sequences of several grape AP genes may be the result of chromosomal rearrangement and fusions. A good case was $V v A P 32$, which had seven exons, but its paralogous gene, $V v A P 21$, had just two exons. Moreover, $V v A P 32$ contained two other domains (RING and DUF1117) besides the ASP domain, and this might have resulted from a mechanism(s) leading to the additional exons. Divergence either in exon/intron length or exon/intron quantity could potentially lead to the generation of functionally distinct paralogs [51].

\section{Functional conservation and divergence of tandem and segmental duplicated AP genes in grape}

As discussed above, tandem and segmental duplication expanded the grape AP gene family, but it should be noted that only one gene in two of the four tandem duplicated paralogs (VvAP5/VvAP6/VvAP7/VvAP8, VvAP22/VvAP23/ $V v A P 24)$ could be included in the phylogenetic tree (Figures 1 and 3), implying that sequences of these genes have been altered to a large extent after gene duplication, 
and may therefore have lost their original functions or gained new ones.

The grape AP genes involved in the tandem and segmental duplication with complete ASP domains, clustered in the same phylogenetic clade (Figure 4A), and had highly similar exon/intron structures (Figure 4C); however, in different tissues and/or under a variety of stress or hormone treatments, the transcript abundance of the two genes within each pair of paralogs varied from each other (Figures 5 and 6). Although the expression patterns of $V v A P 34$ and $V v A P 35$ under each treatment were almost identical, different expression levels could be observed in the same plant organ. The expression of another pair of tandem duplicated paralogs, $V v A P 3$ and $V v A P 4$, were barely detectable under the various treatments, but slight expression of $V v A P 3$ could be detected in the stems and tendrils of 'Kyoho'. Regarding the segmental duplication paralogs, almost all of the two AP genes within each pair of paralogs showed different transcript levels under three or four of the five treatments, and exhibited similar transcript abundance under the other one or two treatments. One exception was VvAP17/ $V v A P 42$, whose transcript levels were totally different under all of the five treatments. These results are similar to findings in rice [46], which showed that not all OsAP genes in the same category had similar expression patterns, and OsAP genes classified in the same expression pattern might have a distant phylogenetic relationship.

It seems possible that high sequence similarity is not necessarily correlated with similar transcript levels, because proteins with very similar sequences, presumably performing similar biochemical functions, are needed in different tissues and at different periods during growth and development, while at the same time responding to different stresses and hormone treatments. Similar transcript abundance exhibited by different AP genes with dissimilar sequences may perform different biochemical functions, suggesting they may work together in the tissues during growth and development or in response to the same stress or hormone treatment.

It has been reported that duplicated genes rarely diverge with respect to their biochemical function, but instead are limited to alterations in regulatory control [58]. So the different expression profiles between duplicated genes may be caused by varied regulatory network or mutations in the cis-regulatory regions [59], or mutations affecting the related regulatory network [60,61]. Epigenetic mechanisms, such as DNA methylation have also been suggested to potentially contribute to the expression divergence of duplicated genes $[62,63]$, where transcriptional silencing has often been associated with DNA methylation in promoter regions $[64,65]$.

A large part of expression divergence is considered to arise through duplication in the course of evolution [45], and functional diversification of the surviving duplicated genes is also considered a major feature of the long-term evolution of polyploids [66]. It has been reported that four types of functional differentiation may follow gene duplication: pseudogenization, conservation of gene function, subfunctionalization and neofunctionalization [67]. Many duplicated genes may be lost from the genome after the duplication events, while neofunctionalization and subfunctionalization contribute to the retention of new genes. The $V v A P$ gene family presents an opportunity to study how expression has diverged following gene duplication. Similar transcript abundance between duplicated genes, such as VvAP34 and VvAP35, suggest that the regulatory mechanism of their expression have been conserved; on the other hand, divergence in expression patterns of the duplicated AP genes (neofunctionalization or subfunctionalization) could reflect the acquisition of novel regulatory mechanisms, while silencing of gene expression after duplication leading to nonfunctionalization of the gene implies drastic alteration of the regulatory mechanism.

Besides the possibilities that have been discussed above, the differences in specificity/catalytic properties and cellular localization among/between the duplicated genes could also contribute to the development of different biological functions, leading to the observed expression divergence $[6,68,69]$. It was found that almost all of the AP genes within each pair of paralogs were located in different parts of the cell, with two exceptions of $V v A P 3 / V v A P 4$ (both in the nucleus), and $V v A P 17 / V v A P 42$ (both in the plasma membrane) (Additional file 11). Even if these paralogs shared similar gene structure and cellular localization, the diversity of expression of these genes may be the result of alterations in regulatory sequences occurring shortly after duplication. In addition, alteration of function could also result from the presence or absence of protein-processing enzymes responsible for the activation/ deactivation of the enzymes [6].

In summary, diversity in the transcript levels of the duplicated genes may be affected by different and multiple genetic factors depending on the causal duplication mechanism [70], and there maybe cross talk between different treatments or regulatory mechanisms. More research is needed to clarify the specifics of any functional divergence between grape duplicated AP genes, and new factors that may affect transcript divergence and how different factors work together are worth investigation.

\section{The evolution of AP proteins in grape and Arabidopsis and functional prediction of grape AP genes}

Genomic comparison is a quick way to transfer knowledge acquired in one taxon for which there is a better understanding of genome structure and function to a 
less-studied taxon [71]. Thus, the richness of gene functional information known for model plants such as Arabidopsis enables one to extrapolate functions of their orthologous genes in other plant taxa. To obtain an overall picture of the grape AP proteins and their relationships with those of Arabidopsis, both syntenic and phylogenetic analyses have been performed, and the evolutionary relationship of this gene family within and among the different species has been systematically studied.

There were 23 grape and 25 Arabidopsis AP genes, as well as the other four Arabidopsis genes that were syntenic orthologous (Figure 2, Additional file 4). Among these, 10 were single grape-to-Arabidopsis AP orthologs, indicating these genes come from a common ancestor. The other genes constituted a more complex situation, including ten cases of two grape AP genes that corresponded to one Arabidopsis AP gene, 10 cases of one grape AP gene corresponding to multiple Arabidopsis AP genes, and three cases of two duplicated grape AP genes that corresponded to multiple Arabidopsis AP genes. Certainly, most of the genes included in the complex situation appeared more than once. For example, VvAP27 correspondence to At1g11910 and At1g62290 located on the Chr1 of Arabidopsis, as well as At4g04460 and At4g022050 located on the Chr4 of Arabidopsis, and VvAP45 correspondence to At1g11910, At1g62290 and At4022050, but not to At4g04460, so it is impossible to elucidate whether divergence of $V v A P 27$ and $V v A P 45$ located in segmental duplications of grape and At1g11910, At1g62290, At4022050 and At4g04460 in Arabidopsis occurred prior to or after the divergence of grape and Arabidopsis from the last common ancestor. Although 27 grape AP genes could not be mapped into any syntenic blocks, we could not conclude that these genes from grape and Arabidopsis did not share a common ancestor. This may be explained by the fact that after the divergence of lineages that led to grape and Arabidopsis, their genomes underwent multiple rounds of significant chromosomal rearrangement and fusions, followed by selective gene loss, which can severely obscure the identification of chromosomal syntenies [72]. In such case, it maybe concluded that some of the AP genes in grape and Arabidopsis come from a common ancestor, while the others do not. Although the evolutionary histories of grape AP genes could not be established for the period prior to the split between grape and Arabidopsis lineages, at least some of the grape genes appeared to share a common ancestor with their Arabidopsis AP counterparts.

In order to improve prediction of the functions of specific grape AP genes based on the reported function of their Arabidopsis homologs, a phylogenetic tree was constructed, and bootstrap support values (1000 re-sampling) exceeding $50 \%$ were used to identify possible orthologous pairs (Figure 3). For example, VvAP30 and At4g30030 were clustered together in the phylogenetic tree, but the bootstrap value of their node was no more than $50 \%$. Therefore, VvAP3O and At4g30030 were excluded from the orthologous pairs, as were $V v A P 13$ and At1g08210/ At5g22850, VvAP16/VvAP44 and At3g50050, VvAP27 and At4g04460, VvAP17/VvAP42 and At5g10080, VvAP46 and At3g12700. There were 11 orthologous pairs in the phylogenetic tree that could not be detected in the syntenic orthologs, and 21 syntenic orthologs that could not be detected or were not clustered together in the phylogenetic tree (Additional file 4, Additional file 5, Additional file 12). Thus, there were ten orthologs including 8 grape AP genes (VvAP27/VvAP45-At1g11910/At1g62290, VvAP39At1g49050, VvAP21-At5g02190, VvAP25-At2g36670, VvAP 32-At2g39710, VvAP33-At3g54400 and VvAP44-At5g4 3100 ) that could be clustered together in the phylogenetic tree and were also contained in the syntenic map (Additional file 5, Additional file 12). Expression patterns of the ten orthologs were more similar than other orthologous pairs that only clustered together in the phylogenetic tree or were syntenic orthologs (Additional file 12). As a result, we can speculate that the functions of the eight grape AP genes are more similar to their Arabidopsis homologs than the other grape APs in the phylogenetic tree and syntenic map. Ling et al. [73] has used phylogeny-based methods to identify orthologs between Arabidopsis and cucumber, and further analyzed the correlation of roles of orthologous pairs under abiotic stresses. Their results showed that correlative expression profiles in stress-inducible orthologous WRKY genes between cucumber and Arabidopsis and orthologous WRKY genes with different evolutionary patterns displayed a low correlation in their expression patterns [73]. Our study combining synteny analysis with a phylogenetic tree provides new insight for investigating the function of grape AP genes by comparing orthologous genes between two plants, in one of which functional roles for the genes have been identified, in this case, between grape and Arabidopsis.

\section{VvAP proteins play important roles in a range of biological processes}

It has been reported that plant APs are implicated in a variety of biological processes [6,7]. The study on the rice AP gene family showed that 66 genes were presented in at least one of the developmental stages analyzed [46]. Timotijevic et al. [74] isolated an aspartic proteinase gene FeAP12 from developing buckwheat seeds, and found the gene was seed-specifically expressed. Moreover, the highest levels of FeAP12 expression were observed in the early stages of seed development, suggesting a potential role in nucellar degradation [74]. Our RT-PCR results showed that most of the $V v A P$ genes exhibited diverse 
expression levels in all six organs, indicating these APs often participate in plant development. Genes which showed higher expression levels in one organ than in others may play key roles in the development process of the corresponding organ. It was worth noting that the expression of $V v A P 36$ could only be detected in stems, indicating its potential role in the stem development.

Evidence is accumulating that AP proteins are involved in plant responses to various abiotic and biotic stresses. Cruz et al. [75] reported that in drought-susceptible common bean cultivars subjected to water deficit, the expression of an AP gene was shown to be transcriptionally up-regulated and its activity was significantly increased. In recently published reports, Yao et al. [20] have shown that an Arabidopsis gene, ASPG1 (aspartic protease in guard cell 1), may function in drought avoidance through abscisic acid (ABA) signaling in guard cells. An aspartic protease gene, FeAP9, whose expression was up-regulated in leaves under different abiotic stresses has also been found in developing organs of buckwheat [69]. In the present study, we showed that 18 $V v A P$ genes exhibited differential transcript abundance in response to at least one abiotic stress (Figure 6), indicating that $V \nu A P$ genes may play an important role in protecting grape from abiotic stresses.

Expression of an extracellular AP gene has also been detected in tobacco and tomato leaves and implicated in the degradation of pathogenesis-related (PR) proteins. It has been suggested that APs may play a role in a conserved mechanism for PR-protein turnover, preventing over accumulation and thereby regulating the biological functions of these stress induced proteins [76,77]. These APs were also shown to be constitutively expressed either in healthy or infected leaves, which was consistent with our findings in this study. Studies with potato showed that the expression levels of StAPS were associated with the degree of resistance of potato cultivars to Phytophthora infestans, and potato aspartic proteinases were components of the plant defense response [78]. Xia et al. [11] have also shown the accumulation of an AP gene, CDR1 (Constitutive disease resistance), in response to pathogen attacks. The CDR1 gene in rice has also been studied, and the results suggested that OsCDR1 was implicated in disease resistance signaling [10]. Powdery mildew, caused by the obligate biotrophic fungus, Uncinula necator, has a serious impact on grape productivity and fruit quality [79]. As shown in Figure 6, four of the grape AP genes exhibited increased transcript abundance in the infected leaves, indicating these genes may participate in the plant response to powdery mildew infection. It has been reported that the PSI may take part in defensive mechanisms against pathogens and/or as an effector of cell death [6], but none of the grape AP genes in group A1 was upregulated upon powdery mildew infection. However, we cannot conclude that the $V v A P S$ in group A1 have no function in defensive against pathogens, because they may participate in resistance against other pathogens.

Besides the functions of APs in response to abiotic and/ or biotic stress, some APs were reported to be involved in PCD (programmed cell death) [80]. In addition, nucellin, an AP belonging to group B subfamily and known to be expressed specifically in nucellar cells during degeneration after ovule fertilization in barely, was suggested to be involved in PCD [9]. So we can speculate that $V v A P s$ in group B is also involved in various types of PCD [81].

Differences of the cellular localization of AP genes may result in their different biological functions $[6,68,69]$, and it has been reported that most plant APs were vacuolar enzymes [82-85], or were secreted to the cell wall[86,87]. But there were many aspartic proteinases in Arabidopsis and one third of the grape AP genes were predicted to be localized to the chloroplast and chloroplast thylakoid membrane, respectively [7] (Additional file 11). In tobacco, one chloroplast-located AP gene named CND41 (for $41 \mathrm{kD}$ Chloroplast Nucleoid DNA-binding protein) is involved in degradation of the Rubisco holoprotein during leaf senescence, and the accumulation of CND41 is negatively correlated with chloroplast transcript levels in tobacco cells [88-90]. The homologs of CND41 in Arabidopsis have also been confirmed to participate in the regulation of Rubisco turnover and senescence [91-93]. In a more recently published report, Paparelli et al. [94] have identified a chloroplast-located AP gene NANA whose misexpression or overexpression not only influences photosynthetic carbohydrate metabolism but also plastid and nuclear gene expression [94]. So the localization of these AP genes to the Arabidopsis or grape thylakoid membranes raises the possibility that they may fulfill roles as specific processing enzymes in this organelle, or participate in maintenance or degradation of photosystem proteins $[7,95]$.

To get a more complete understanding of the biological functions of the AP gene family, identification of substrates that AP proteins act on and the regulatory network of AP genes participating in response to various pathogens are necessary. The results presented here indicate that the regulatory role of AP proteins under abiotic and biotic stress is complex and more work is needed to understand the regulatory mechanisms.

\section{Conclusions}

In the present study, we identified a total of 50 grape AP genes, 30 of which had complete ASP domains. Synteny analysis within grape demonstrated that segmental and tandem duplications have contributed to the expansion of the grape AP gene family. Comparative synteny analysis between the $V$. vinifera and Arabidopsis genomes indicated that some of the grape and Arabidopsis AP 
genes were located in syntenic regions, suggesting that these genes had common ancestors. Separation of the grape AP genes into three groups was mutually supported by their phylogeny, exon/intron structure and the distribution of conserved domains. Finally, we analyzed expression profiles of $30 \mathrm{VvAP}$ genes that possess a complete ASP domain under normal growth conditions and in response to various abiotic and biotic stresses and hormone treatments. Some of the genes evaluated were not expressed in leaves of 'Kyoho' and/or 'Shang-24'. The expression information reported here will be useful for further investigation of the function of AP genes under various stress conditions. Although the genome sequence of grape has been reported, functional studies on grape genes still lag behind. We integrated the synteny analysis between grape and Arabidopsis with a phylogenetic tree of the two species, and found that there were ten orthologs, including eight grape AP genes clustered together in the phylogenetic tree and also contained in the syntenic map. Although correlation of the expression of orthologous AP genes in grape and Arabidopsis was not calculated, the method of combining synteny analysis with the phylogenetic tree may provide a new approach for investigating gene function from their orthologs whose functions have been previously clarified. These studies could increase our understanding of the roles of these genes in grape, but further functional analysis of stress-responsive VvAPS is required to confirm their role in stress tolerance.

\section{Additional files}

\section{Additional file 1: The primer sequences used for semi-quantitative RT-PCR of the selected positive control genes for salt, drought, powdery mildew, SA and ABA treatments. The specific primers were obtained from published reports. \\ Additional file 2: The primer sequences used for semi-quantitative RT-PCR amplification of $30 \mathrm{VvAP}$ genes. The specific primers were designed according to the AP gene sequence by Primer 5.0 software. Additional file 3: Synteny blocks of AP genes within the grape genome. The data were downloaded from the Plant Genome Duplication Database, and those containing grape AP genes were identified.}

Additional file 4: Synteny blocks of AP genes between grape and Arabidopsis genomes. The data were downloaded from the Plant Genome Duplication Database, and those containing grape AP genes were identified.

Additional file 5: Putative orthologs of grape and Arabidopsis. Grape AP proteins and their putative orthologs in Arabidopsis were identified based on phylogenetic studies of ASP domain sequences.

Additional file 6: Expression patterns of grape AP genes under salt treatment condition. A. Expression patterns of $25 \mathrm{AP}$ genes under salt treatment conditions were determined by semi-quantitative RT-PCR analyses. For each gene, the upper six amplification bands represent amplified products from leaves of 'Kyoho' after treatment with $2 \mathrm{dm}^{3}$ $250 \mathrm{mM} \mathrm{NaCl}$; the bands under them represent amplified products from leaves of the control. B. Expression patterns of three randomly selected AP genes were analyzed by real-time RT-PCR. The grape Actin 1 and EF1-a genes were used as internal controls to normalize the data. VVRD22 served as a positive control for salt stress. The error bars were calculated based on three replicates.

Additional file 7: Expression patterns of grape AP genes under drought treatment. A. Expression patterns of $25 \mathrm{AP}$ genes under drought treatment conditions were determined by semi-quantitative RT-PCR analyses. For each gene, the upper eight amplification bands represent amplified products from leaves of 'Kyoho' under drought stress for $24 \mathrm{~h}, 48 \mathrm{~h}, 72 \mathrm{~h}, 96 \mathrm{~h}, 120 \mathrm{~h}, 144 \mathrm{~h}, 168 \mathrm{~h}$ after $48 \mathrm{~h}$ of recovery (R48; rewatered); the bands under them represent amplified products from leaves of the control. B. Expression patterns of three randomly selected AP genes were detected by real-time PCR. VVRD22 was used as a positive control.

Additional file 8: Expression patterns of grape AP genes under powdery mildew treatment. A. Expression patterns of 23 AP genes under PM treatment condition were determined by semi-quantitative RTPCR analyses. For each gene, the upper seven amplification bands represent amplified products from leaves of 'Shang-24' after inocululation with powdery mildew; the bands under them represent amplified products from Mock-inoculated leaves. B. Expression patterns of three randomly selected AP genes were detected by real-time PCR. VVPR1 was used as a positive control.

Additional file 9: Expression patterns of grape AP genes under SA treatment. A. Expression patterns of 25 AP genes under SA treatment conditions were determined by semi-quantitative RT-PCR analyses. For each gene, the upper seven amplification bands represent amplified products from leaves of 'Kyoho' after treatment with $100 \mu \mathrm{M} \mathrm{SA}$; the bands under them represent amplified products from control leaves. B. Expression patterns of three randomly selected AP genes were analyzed by real-time PCR. VVEDS1 was used as a positive control.

Additional file 10: Expression patterns of grape AP genes under ABA treatment. A. Expression patterns of $25 \mathrm{AP}$ genes under ABA treatment conditions were determined by semi-quantitative RT-PCR analyses. For each gene, the upper seven amplification bands represent amplified products from leaves of 'Kyoho' after treatment with $100 \mu \mathrm{M}$ $A B A$; the bands under them represent amplified products from control leaves. B. Expression patterns of three randomly selected AP genes were determined by real-time PCR. VVCEF4 was used as a positive control.

Additional file 11: The cellular localization of grape APs.

Additional file 12: Comparison of expression pattern of orthologous AP pairs under various stresses and treatments. Available expression patterns of AtAP genes based on microarray analysis and that of VVAP genes generated by semi-quantitative RT-PCR were compared.

\section{Abbreviations}

AP: Aspartic protease; CDR1: Constitutive disease resistance gene 1; PCS1: Promotion of cell survival gene 1; ASPG1: Aspartic protease in guard cell 1; WGD: Whole genome duplication; NJ: Neighbor-joining; SA: Salicylic acid; ABA: Abscisic acid; RT-PCR: Reverse transcription PCR; Hpt: Hours post-treatment; R48: 48-hour after rewatering; Hpi: Hours post-inoculation; PR: Pathogenesis-related; PCD: Programmed cell death.

\section{Competing interests}

The authors declare that they have no competing interests.

\section{Authors' contributions}

$X W, R G$ designed the study. RG and YZ performed data analysis. XX, MG and $X L$ contributed to abiotic and hormone treatments. RG and $X L$ did the RT-PCR and GRT-PCR analysis. XW provided guidance on the whole study. $\mathrm{RG}$ and XW wrote and revised the manuscript. CLB assisted with the interpretation of the results and provided editorial support for the manuscript. All authors approved the final manuscript.

\section{Acknowledgements}

The authors thank Dr. Zongrang Liu and Dr. Zhangjun Fei for critical revision of this manuscript. This work was supported by the National Natural Science Foundation of China (31071782), 948 Project from Ministry of Agriculture of China (2012-S12), Chinese Universities Scientific Fund (QN2011056), as well as the Program for Innovative Research Team of Grape Germplasm Resources and Breeding (2013KCT-25). 


\section{Author details}

'State Key Laboratory of Crop Stress Biology in Arid Areas, College of Horticulture, Northwest A\&F University, Yangling, Shaanxi 712100, China. ${ }^{2}$ Key Laboratory of Horticultural Plant Biology and Germplasm Innovation in Northwest China, Ministry of Agriculture, Northwest A\&F University, Yangling, Shaanxi 712100, China. ${ }^{3}$ Agricultural Research Service, Appalachian Fruit Research Station, United States Department of Agriculture, Kearneysville W 25430, USA.

Received: 12 December 2012 Accepted: 6 August 2013

Published: 15 August 2013

\section{References}

1. Barrett AJ: Cellular proteolysis - an overview. Ann NY Acad Sci 1992 674:1-15.

2. Davies DR: The structure and function of the aspartic proteinases. Annu Rev Biophys Biophys Chem 1990, 19:189-215.

3. Rawlings ND, Barrett AJ: MEROPS: the peptidase database. Nucleic Acids Res 1999, 27(1):325-331.

4. John K: Aspartic proteinases and their inhibitors. In FEBS Advanced Course. Edited by Kostka V. Berlin: Walter de Gruyter; 1985:1-17.

5. Flotman B: Comments on the nomenclature of aspartic proteinases. In FEBS Advanced Course. Edited by Kostka V. Berlin: Walter de Gruyter; 1985:19-26.

6. Simoes I, Faro C: Structure and function of plant aspartic proteinases. Eur J Biochem 2004, 271(11):2067-2075.

7. Faro C, Gal S: Aspartic proteinase content of the Arabidopsis genome. Curr Protein Pept Sc 2005, 6(6):493-500.

8. Mutlu A, Gal S: Plant aspartic proteinases: enzymes on the way to a function. Physiol Plantarum 1999, 105(3):569-576.

9. Chen FQ, Foolad MR: Molecular organization of a gene in barley which encodes a protein similar to aspartic protease and its specific expression in nucellar cells during degeneration. Plant Mol Biol 1997, 35(6):821-831.

10. Prasad BD, Creissen G, Lamb C, Chattoo BB: Heterologous expression and characterization of recombinant OsCDR1, a rice aspartic proteinase involved in disease resistance. Protein Expres Purif 2010, 72(2):169-174.

11. Xia YJ, Suzuki H, Borevitz J, Blount J, Guo ZJ, Patel K, Dixon RA, Lamb C: An extracellular aspartic protease functions in Arabidopsis disease resistance signaling. EMBO J 2004, 23(4):980-988.

12. Jaillon O, Aury JM, Noel B, Policriti A, Clepet C, Casagrande A, Choisne N, Aubourg S, Vitulo N, Jubin C, et al: The grapevine genome sequence suggests ancestral hexaploidization in major angiosperm phyla. Nature 2007, 449(7161):463-465.

13. Velasco R, Zharkikh A, Troggio M, Cartwright DA, Cestaro A, Pruss D, Pindo M, FitzGerald LM, Vezzulli S, Reid J, et al: A high quality draft consensus sequence of the genome of a heterozygous grapevine variety. Plos One 2007, 2(12):e1326.

14. Goff SA, Ricke D, Lan TH, Presting G, Wang RL, Dunn M, Glazebrook J, Sessions A, Oeller $P$, Varma $H$, et al: A draft sequence of the rice genome (Oryza sativa L. ssp japonica). Science 2002, 296(5565):92-100.

15. Tuskan GA, DiFazio S, Jansson S, Bohlmann J, Grigoriev I, Hellsten U, Putnam N, Ralph S, Rombauts S, Salamov A, et al: The genome of black cottonwood, Populus trichocarpa (Torr. \& Gray). Science 2006, 313(5793):1596-1604.

16. Riechmann JL, Heard J, Martin G, Reuber L, Jiang CZ, Keddie J, Adam L, Pineda O, Ratcliffe OJ, Samaha RR, et al: Arabidopsis transcription factors: genome-wide comparative analysis among eukaryotes. Science 2000, 290(5499):2105-2110.

17. Zhang YC, Mao LY, Wang H, Brocker C, Yin XJ, Vasiliou V, Fei ZJ, Wang XP: Genome-wide identification and analysis of grape aldehyde dehydrogenase (ALDH) gene superfamily. Plos One 2012, 7(2):e32153.

18. Larkin MA, Blackshields G, Brown NP, Chenna R, McGettigan PA, McWilliam H, Valentin F, Wallace IM, Wilm A, Lopez R, et al: Clustal W and Clustal X version 2.0. Bioinformatics 2007, 23(21):2947-2948.

19. Ge XC, Dietrich C, Matsuno M, Li GJ, Berg H, Xia YJ: An Arabidopsis aspartic protease functions as an anti-cell-death component in reproduction and embryogenesis. EMBO Rep 2005, 6(3):282-288.

20. Yao $X$, Xiong $W, Y e T, W u$ Y: Overexpression of the aspartic protease ASPG1 gene confers drought avoidance in Arabidopsis. J Exp Bot 2012, 63(7):2579-2593.
21. Tamura K, Peterson D, Peterson N, Stecher G, Nei M, Kumar S: MEGA5: molecular evolutionary genetics analysis using maximum likelihood, evolutionary distance, and maximum parsimony methods. Mol Biol Evol 2011, 28(10):2731-2739.

22. Letunic I, Doerks T, Bork P: SMART 7: recent updates to the protein domain annotation resource. Nucleic Acids Res 2012, 40(D1):D302-D305.

23. Ren J, Wen LP, Gao XJ, Jin CJ, Xue Y, Yao XB: DOG 1.0: illustrator of protein domain structures. Cell Res 2009, 19(2):271-273.

24. Rice P, Longden I, Bleasby A: EMBOSS: the European molecular biology open software suite. Trends Genet 2000, 16(6):276-277.

25. Guo $A Y$, Zhu QH, Chen X, Luo JC: GSDS: a gene structure display server. Yi Chuan 2007, 29(8):1023-1026.

26. Boneh U, Biton I, Zheng CL, Schwartz A, Ben-Ari G: Characterization of potential ABA receptors in Vitis vinifera. Plant Cell Rep 2012, 31(2):311-321.

27. Upreti KK, Murti GSR: Response of grape rootstocks to salinity: changes in root growth, polyamines and abscisic acid. Biol Plantarum 2010, 54(4):730-734

28. Cramer GR, Ergul A, Grimplet J, Tillett RL, Tattersall EAR, Bohlman MC, Vincent D, Sonderegger J, Evans J, Osborne C, et al: Water and salinity stress in grapevines: early and late changes in transcript and metabolite profiles. Funct Integr Genomic 2007, 7(2):111-134.

29. Yang YZ, He MY, Zhu ZG, Li SX, Xu Y, Zhang CH, Singer SD, Wang YJ: Identification of the dehydrin gene family from grapevine species and analysis of their responsiveness to various forms of abiotic and biotic stress. BMC Plant Biol 2012, 12:140.

30. Li HE, XU Y, Xiao Y, Zhu ZG, Xie XQ, Zhao HQ, Wang YJ: Expression and functional analysis of two genes encoding transcription factors, VpWRKY1 and VpWRKY2, isolated from Chinese wild Vitis pseudoreticulata. Planta 2010, 232(6):1325-1337.

31. Wang LJ, Li SH: Thermotolerance and related antioxidant enzyme activities induced by heat acclimation and salicylic acid in grape (Vitis vinifera L.) leaves. Plant Growth Regul 2006, 48(2):137-144.

32. Xiao HG, Nassuth A: Stress- and development-induced expression of spliced and unspliced transcripts from two highly similar dehydrin 1 genes in V, riparia and V, vinifera. Plant Cell Rep 2006, 25(9):968-977.

33. Wang Y, Liu Y, He P, Chen J, Lamikanra O, Lu J: Evaluation of foliar resistance to uncinula necator in Chinese wild Vitis species. Vitis 1995, 34(3):159-164.

34. Volker HDC, Jose LR, Omaira P, Michael FT, James ZZ: Transcription factor CBF4 is a regulator of drought adaptation in Arabidopsis. Plant Physiol 2002, 130:639-648.

35. Mahbuba SAN: Vitis CBF1 and Vitis CBF4 differ in their effect on Arabidopsis abiotic stress tolerance, development and gene expression. Plant Cell Environ 2011, 34:1345-1359.

36. Mohsen HLD, Romain F, Samia D, Celine L, Francois B, Abdelwahed G, Ahmed M, Said H: Identification and characterization of ' $r d 22$ ' dehydration responsive gene in grapevine (Vitis vinifera L.). C R Biol 2008, 331(8):569-578.

37. Wang Q, Zhang YC, Gao M, Jiao C, Wang XP. Identification and expression analysis of a pathogen-responsive PR-1 gene from Chinese wild Vitis quinquangularis. Afr J Biotechnol 2011, 10(75):17062-17069.

38. Loake G: Plant cell death: unmasking the gatekeepers. Curr Biol 2001, 11(24):R1028-R1031.

39. Brodersen P, Petersen M, Nielsen HB, Zhu SJ, Newman MA, Shokat KM, Rietz S, Parker J, Mundy J: Arabidopsis MAP kinase 4 regulates salicylic acidand jasmonic acid/ethylene-dependent responses via EDS1 and PAD4. Plant J 2006, 47(4):532-546.

40. Chong JL, Le Henanff G, Bertsch C, Walter B: Identification, expression analysis and characterization of defense and signaling genes in Vitis vinifera. Plant Physiol Bioch 2008, 46(4):469-481.

41. Zhang JJ, Wang YJ, Wang XP, Yang KQ, Yang JX: An improved method for rapidly extracting total RNA from Vitis. Fruit Sci 2003, 53:771-787.

42. Kapushesky M, Emam I, Holloway E, Kurnosov P, Zorin A, Malone J, Rustici G, Williams E, Parkinson H, Brazma A: Gene expression atlas at the European bioinformatics institute. Nucleic Acids Res 2010, 38:D690-D698.

43. Schmid M, Davison TS, Henz SR, Pape UJ, Demar M, Vingron M, Scholkopf B, Weigel D, Lohmann JU: A gene expression map of Arabidopsis thaliana development. Nature Genet 2005, 37(5):501-506.

44. Kenta NMK: A knowledge base for predicting protein localization sites in eukaryotic cells. Genomics 1992, 14(4):897-911. 
45. Cannon SB, Mitra A, Baumgarten A, Yong ND, May G: The roles of segmental and tandem gene duplication in the evolution of large gene families in Arabidopsis thaliana. BMC Plant Biol 2004, 4:10.

46. Chen JJ, Ouyang YD, Wang L, Xie WB, Zhang QF: Aspartic proteases gene family in rice: gene structure and expression, predicted protein features and phylogenetic relation. Gene 2009, 442(1-2):108-118.

47. Barrett AJ, Rawlings ND, Woessner JF: Handbook of proteolytic enzymes. Amsterdam: Elsevier Academic Press; 2004

48. Munoz FF, Mendieta JR, Pagano MR, Paggi RA, Daleo GR, Guevara MG: The swaposin-like domain of potato aspartic protease (StAsp-PSI) exerts antimicrobial activity on plant and human pathogens. Peptides 2010 31(5):777-785.

49. Bari $\mathrm{R}$, Jones $\mathrm{J}$ : Role of plant hormones in plant defence responses. Plant Mol Biol 2009, 69(4):473-488.

50. Finkelstein RR, Gampala SSL, Rock CD: Abscisic acid signaling in seeds and seedlings. Plant Cell 2002, 14:S15-S45

51. Xu GX, Guo CC, Shan HY, Kong HZ: Divergence of duplicate genes in exon-intron structure. P Natl Acad Sci USA 2012, 109(4):1187-1192.

52. Doyle JJ, Flagel LE, Paterson AH, Rapp RA, Soltis DE, Soltis PS, Wendel JF: Evolutionary genetics of genome merger and doubling in plants. Annu Rev Genet 2008, 42:443-461.

53. Gambetta GA, Matthews MA, Shaghasi TH, McElrone AJ, Castellarin SD: Sugar and abscisic acid signaling orthologs are activated at the onset of ripening in grape. Planta 2010, 232(1):219-234.

54. Hurley I, Hale ME, Prince VE: Duplication events and the evolution of segmental identity. Evol Dev 2005, 7(6):556-567.

55. Kellis M, Birren BW, Lander ES: Proof and evolutionary analysis of ancient genome duplication in the yeast Saccharomyces cerevisiae. Nature 2004, 428(6983):617-624.

56. Wolfe $\mathrm{KH}$, Shields DC: Molecular evidence for an ancient duplication of the entire yeast genome. Nature 1997, 387(6634):708-713.

57. Li WY, Liu B, Yu LJ, Feng DR, Wang HB, Wang JF: Phylogenetic analysis, structural evolution and functional divergence of the 12-oxophytodienoate acid reductase gene family in plants. BMC Evol Biol 2009, 9:90.

58. Wapinski I, Pfeffer A, Friedman N, Regev A: Natural history and evolutionary principles of gene duplication in fungi. Nature 2007, 449(7158):54-U36.

59. Smith $A D$, Sumazin $P, X$ uan $Z Y$, Zhang MQ: DNA motifs in human and mouse proximal promoters predict tissue-specific expression. $P$ Natl Acad Sci USA 2006, 103(16):6275-6280.

60. Wang DY, Sung HM, Wang TY, Huang CJ, Yang P, Chang T, Wang YC, Tseng DL, Wu JP, Lee TC, et al: Expression evolution in yeast genes of single-input modules is mainly due to changes in transacting factors. Genome Res 2007, 17(8):1161-1169.

61. Xing Y, Ouyang ZQ, Kapur K, Scott MP, Wong WH: Assessing the conservation of mammalian gene expression using high-density exon arrays. Mol Biol Evol 2007, 24(6):1283-1285.

62. Chen ZJ, Ni ZF: Mechanisms of genomic rearrangements and gene expression changes in plant polyploids. Bioessays 2006, 28(3):240-252.

63. Rapp RA, Wendel JF: Epigenetics and plant evolution. New Phytol 2005, 168(1):81-91.

64. Zhang XY, Yazaki J, Sundaresan A, Cokus S, Chan SWL, Chen HM, Henderson IR, Shinn P, Pellegrini M, Jacobsen SE, et al: Genome-wide high-resolution mapping and functional analysis of DNA methylation in Arabidopsis. Cell 2006, 126(6):1189-1201.

65. Zilberman D, Gehring M, Tran RK, Ballinger T, Henikoff S: Genome-wide analysis of Arabidopsis thaliana DNA methylation uncovers an interdependence between methylation and transcription. Nature Genet 2007, 39(1):61-69.

66. Blanc $\mathrm{G}$, Wolfe $\mathrm{KH}$ : Functional divergence of duplicated genes formed by polyploidy during Arabidopsis evolution. Plant Cell 2004, 16(7):1679-1691.

67. Zhang JZ: Evolution by gene duplication: an update. Trends Ecol Evol 2003, 18(6):292-298.

68. Dunn BM: Structure and mechanism of the pepsin-like family of aspartic peptidases. Chem Rev 2002, 102(12):4431-4458.

69. Timotijevic GS, Milisavljevic MD, Radovic SR, Konstantinovic MM, Maksimovic VR: Ubiquitous aspartic proteinase as an actor in the stress response in buckwheat. J Plant Physiol 2010, 167(1):61-68.

70. Wang YP, Wang XY, Tang HB, Tan X, Ficklin SP, Feltus FA, Paterson AH: Modes of gene duplication contribute differently to genetic novelty and redundancy, but show parallels across divergent angiosperms. Plos One 2011, 6(12):e28150.

71. Lyons E, Pedersen B, Kane J, Alam M, Ming R, Tang HB, Wang XY, Bowers J, Paterson A, Lisch D, Freeling M: Finding and comparing syntenic regions among Arabidopsis and the outgroups papaya, poplar, and grape: CoGe with rosids. Plant Physiol 2008, 148:1772-1781.

72. Zhang YC, Gao M, Singer SD, Fei ZJ, Wang H, Wang XP: Genome-wide identification and analysis of the tify gene family in grape. Plos One 2012, 7(9):e44465

73. Ling J, Jiang WJ, Zhang Y, Yu HJ, Mao ZC, Gu XF, Huang SW, Xie BY: Genome-wide analysis of WRKY gene family in Cucumis sativus. BMC Genomics 2011, 12:471.

74. Timotijevic GS, Milisavljevic MD, Radovic SR, Konstantinovic MM, Maksimovic VR: Seed-specific aspartic proteinase feap12 from buckwheat (Fagopyrum esculentum Moench). Arch Biol Sci 2010, 62(1):143-151.

75. de Carvalho MHC, d'Arcy-Lameta A, Roy-Macauley H, Gareil M, El Maarouf H, Pham-Thi AT, Zuily-Fodil Y: Aspartic protease in leaves of common bean (Phaseolus vulgaris L.) and cowpea (Vigna unguiculata L. Walp): enzymatic activity, gene expression and relation to drought susceptibility. FEBS Lett 2001, 492(3):242-246.

76. Rodrigo I, Vera P, Conejero V: Degradation of tomato pathogenesisrelated proteins by an endogenous 37-kDa aspartyl proteinase. Eur J Biochem 1989, 184:663-669.

77. Rodrigo I, Vera P, Vanloon LC, Conejero V: Degradation of tobacco pathogenesis-related proteins - evidence for conserved mechanisms of degradation of pathogenesis-related proteins in plants. Plant Physiol 1991, 95:616-622.

78. Guevara MG, Oliva CR, Huarte M, Daleo GR: An aspartic protease with antimicrobial activity is induced after infection and wounding in intercellular fluids of potato tubers. Eur J Plant Pathol 2002, 108(2):131-137.

79. Fung RWM, Gonzalo M, Fekete C, Kovacs LG, He Y, Marsh E, Mclntyre LM, Schachtman DP, Qiu WP: Powdery mildew induces defense-oriented reprogramming of the transcriptome in a susceptible but not in a resistant grapevine. Plant Physio/ 2008, 146(1):236-249.

80. Beers EP: Programmed cell death during plant growth and development. Cell Death Differ 1997, 4(8):649-661.

81. Terauchi K, Asakura T, Nishizawa NK, Matsumoto I, Abe K: Characterization of the genes for two soybean aspartic proteinases and analysis of their different tissue-dependent expression. Planta 2004, 218(6):947-957.

82. Runebergroos P, Kervinen J, Kovaleva V, Raikhel NV, Gal S: The aspartic proteinase of barley is a vacuolar enzyme that processes probarley lectin in-vitro. Plant Physiol 1994, 105(1):321-329.

83. Ramalho-Santos M, Verissimo P, Cortes L, Samyn B, Van Beeumen J, Pires E, Faro C: Identification and proteolytic processing of procardosin A. Eur J Biochem 1998, 255(1):133-138

84. Schaaf A, Reski R, Decker EL: A novel aspartic proteinase is targeted to the secretory pathway and to the vacuole in the moss Physcomitrella patens. Eur J Cell Biol 2004, 83(4):145-152.

85. Pereira CS, da Costa DS, Pereira S, Nogueira FD, Albuquerque PM, Teixeira J, Faro C, Pissarra J: Cardosins in postembryonic development of cardoon: towards an elucidation of the biological function of plant aspartic proteinases. Protoplasma 2008, 232(3-4):203-213.

86. Vieira M, Pissarra J, Verissimo P, Castanheira P, Costa Y, Pires E, Faro C: Molecular cloning and characterization of cDNA encoding cardosin B, an aspartic proteinase accumulating extracellularly in the transmitting tissue of Cynara cardunculus L. Plant Mol Biol 2001, 45(5):529-539.

87. da Costa DS, Pereira S, Moore I, Pissarra J: Dissecting cardosin B trafficking pathways in heterologous systems. Planta 2010, 232(6):1517-1530.

88. Kato Y, Murakami S, Yamamoto Y, Chatani H, Kondo Y, Nakano T, Yokota A, Sato F: The DNA-binding protease, CND41, and the degradation of ribulose-1,5-bisphosphate carboxylase/oxygenase in senescent leaves of tobacco. Planta 2004, 220(1):97-104.

89. Murakami S, Kondo Y, Nakano T, Sato F: Protease activity of CND41, a chloroplast nucleoid DNA-binding protein, isolated from cultured tobacco cells. FEBS Lett 2000, 468(1):15-18.

90. Nakano T, Sato F, Yamada Y: Analysis of nucleoid-proteins in tobacco chloroplasts. Plant Cell Physiol 1993, 34(6):873-880.

91. Diaz C, Lemaitre T, Christ A, Azzopardi M, Kato Y, Sato F, Morot-Gaudry JF, Le Dily F, Masclaux-Daubresse C: Nitrogen recycling and remobilization are differentially controlled by leaf senescence and development stage 
in Arabidopsis under low nitrogen nutrition. Plant Physiol 2008 147(3):1437-1449.

92. Kato Y, Yamamoto Y, Murakami S, Sato F: Post-translational regulation of CND41 protease activity in senescent tobacco leaves. Planta 2005, 222(4):643-651.

93. Kato YSN, Yamamoto Y, Sato F: Regulation of senescence by aspartic protease: CND41 in tobacco and CND41 homologues in Arabidopsis. In Photosynthesis: Fundamental Aspects to Global Perspectives: Proceedings of the 13th International Congress on Photosynthesis. Edited by van der Est A, Bruce D, Lawrence BD. KS: Alliance Communications Group; 2005:821-823.

94. Paparelli E, Gonzali S, Parlanti S, Novi G, Giorgi FM, Licausi F, Kosmacz M, Feil $\mathrm{R}$, Lunn JE, Brust H, et al: Misexpression of a chloroplast aspartyl protease leads to severe growth defects and alters carbohydrate metabolism in Arabidopsis. Plant Physiol 2012, 160(3):1237-1250.

95. Almeida CM, Pereira C, da Costa DS, Pereira S, Pissarra J, Simoes I, Faro C: Chlapsin, a chloroplastidial aspartic proteinase from the green algae Chlamydomonas reinhardtii. Planta 2012, 236(1):283-296.

doi:10.1186/1471-2164-14-554

Cite this article as: Guo et al:: Genome-wide identification, evolutionary and expression analysis of the aspartic protease gene superfamily in grape. BMC Genomics 2013 14:554.

\section{Submit your next manuscript to BioMed Central and take full advantage of:}

- Convenient online submission

- Thorough peer review

- No space constraints or color figure charges

- Immediate publication on acceptance

- Inclusion in PubMed, CAS, Scopus and Google Scholar

- Research which is freely available for redistribution 